Bubbles matter: An assessment of the contribution of vapor bubbles to melt inclusion volatile budgets

\title{
Lowell R. Moore
}

Thesis submitted to the faculty of the Virginia Polytechnic Institute and State University in partial fulfillment of the requirements for the degree of

\section{Master of Science \\ In \\ Geosciences}

\author{
Esteban Gazel \\ Robert J. Bodnar \\ Elizabeth Johnson
}

March 18, 2014

Blacksburg, VA

Keywords: melt inclusion, volatiles, Raman spectroscopy, degassing path, $\mathrm{CO}_{2}$ 


\section{Bubbles matter: An assessment of the contribution of vapor bubbles to melt inclusion volatile budgets}

Lowell R. Moore

Abstract

$\mathrm{H}_{2} \mathrm{O}$ and $\mathrm{CO}_{2}$ concentrations of the glass phase in melt inclusions (MI) are commonly used both as a barometer and to track magma degassing behavior during ascent due to the strong pressure dependence of $\mathrm{H}_{2} \mathrm{O}$ and $\mathrm{CO}_{2}$ solubilities in silicate melts. A requirement for this method to be valid is that the glass phase in the MI must represent the composition of the melt that was originally trapped. However, melt inclusions commonly contain a vapor bubble that formed after trapping. Such bubbles may contain $\mathrm{CO}_{2}$ that was originally dissolved in the melt. In this study, we determined the contribution of $\mathrm{CO}_{2}$ in the vapor bubble to the overall $\mathrm{CO}_{2}$ content of $\mathrm{MI}$ based on quantitative Raman analysis of the vapor bubbles in MI from the 1959 Kilauea Iki, 1960 Kapoho, 1974 Fuego volcano, and 1977 Seguam Island eruptions. The bubbles contain up to $90 \%$ or more of the total $\mathrm{CO}_{2}$ in some MI. Reconstructing the original $\mathrm{CO}_{2}$ content by adding the $\mathrm{CO}_{2}$ in the bubble back into the melt results in an increase in $\mathrm{CO}_{2}$ concentration by as much an order of magnitude (1000s of ppm), corresponding to trapping pressures that are significantly greater (by 1 to $>3$ kbars) than one would predict based on analysis of the volatiles in the glass alone. Many MI also showed the presence of a carbonate mineral phase; failure to include its contained $\mathrm{CO}_{2}$ when reconstructing the $\mathrm{CO}_{2}$ content of the originally trapped melt may introduce significant errors in the calculated volatile budget. 


\section{Acknowledgements}

Graduated members of the Virginia Tech Fluids Research Group, Rosario Esposito, Matthew Steele-MacInnis, and Daniel Moncada provided much advice, training, moral support, and constructive feedback during all stages of sample preparation, analysis, data reduction.

Charles Farley, primary technician of the VT Department of Geosciences Vibrational Spectroscopy Lab provided much assistance with Raman analyses.

Current members of the VT Volcanoes Research Group, Pilar Madrigal, Sarah Mazza, Jarek Trela, Lisa Whalen, and William "Ty" Whalen provided constructive feedback during the drafting of this thesis.

My advisors Esteban Gazel, Robert J. Bodnar, and Elizabeth Johnson kept me honest. 


\section{Attributions}

This thesis will be submitted for publication in the journal American Mineralogist as "Moore, L., Gazel, E., Tuohy, R., Lloyd, A., Esposito, R., Hauri, E., Wallace, P. J., Plank, T., Bodnar, R. J. Bubbles matter: An assessment of the contribution of vapor bubbles to melt inclusion volatile budgets."

L. Moore prepared all single-grain and indium mounts of Fuego and Seguam samples, performed all Raman and secondary ion mass spectrometry (SIMS) analyses and all calculations, and drafted the manuscript and figures. E. Gazel, R. Esposito, and R. J. Bodnar aided in the interpretation of major element and volatile chemistry and drafting of the manuscript and figures. A. Lloyd and T. Plank prepared samples from Fuego and Seguam and provided input during the drafting of the manuscript. R. Tuohy and P. J. Wallace prepared and conducted Fourier transform infared spectroscopy on samples from Kilauea Iki and Kapoho and provided input during the drafting of the manuscript. E. Hauri provided assistance and training for SIMS analyses and aided in interpreting the results of SIMS analyses. 


\section{Table of Contents}

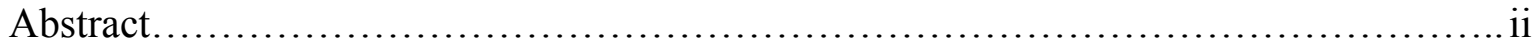

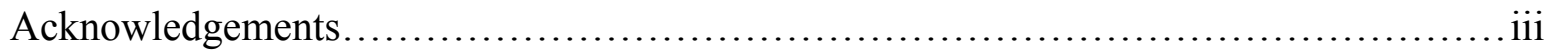

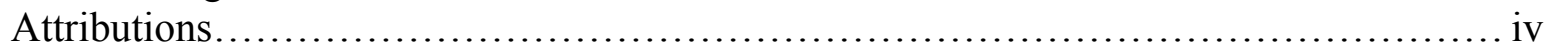

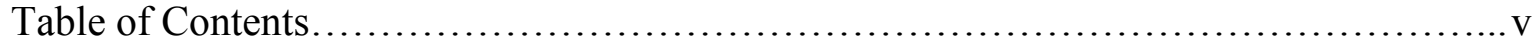

List of Figures......................... vi

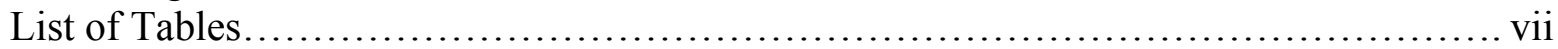

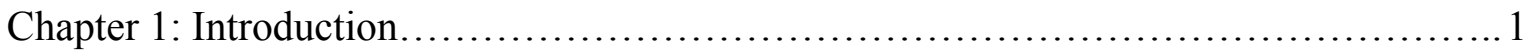

Pseudo degassing paths.....................................................

Quantifying $\mathrm{CO}_{2}$ in MI vapor bubbles..........................................

Chapter 2: Methods......................................................................

Sample collection and preparation...........................................

Raman, SIMS, FTIR and EPMA analysis.................................. 10

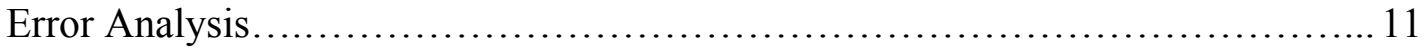

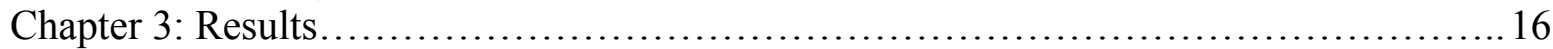

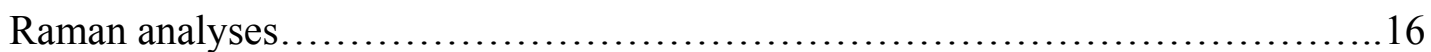

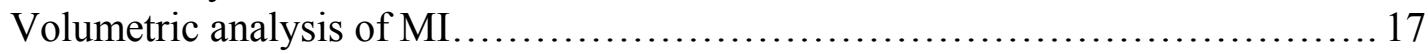

Reconstructing the original $\mathrm{CO}_{2}$ content of the trapped melt..................... 19

The $\mathrm{CO}_{2}$ content of the glass in the $\mathrm{MI}$ is unknown.......................19

The $\mathrm{CO}_{2}$ content of the glass in the $\mathrm{MI}$ is known.......................23

Chapter 4: Discussion.......................................................... 28

Reconstructing the $\mathrm{H}_{2} \mathrm{O}$ content of the MI................................. 28

Reconstruction of MI volatile budgets using PVTX data for melt-volatile systems............................................ 28

Carbonate Phases in Melt Inclusions.............................................31

Revised depths and pressures of formation.................................. 32

Concluding Remarks....................................................... 33

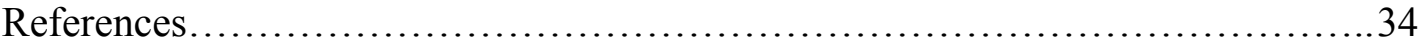

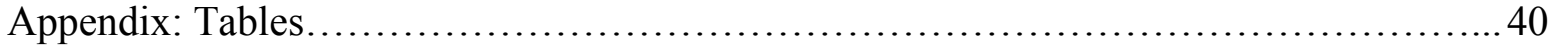




\section{List of Figures}

Figure 1 - A "false" degassing path calculated for a group of MI that all

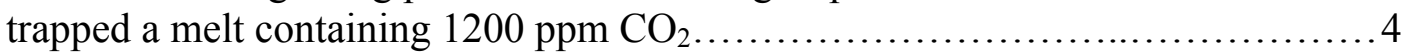

Figure 2 - Raman spectrum of a vapor bubble in an olivine-hosted MI from the 1974 eruption of Fuego volcano.................................................. 6

Figure 3 - Photomicrographs of representative MI................................................ 8

Figure 4 - Calculated isopleths of glass $\mathrm{CO}_{2}$ concentration as a function of $\mathrm{MI}$ glass bulk density and bubble contribution................................. 15

Figure 5 - Plots of MI volume and bubble volume and contours of volume

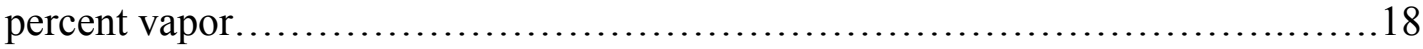

Figure 6 - The density of $\mathrm{CO}_{2}$ contained in the bubbles of glassy $\mathrm{MI}$ as a function of the volume percent bubble in MI........................................ 21

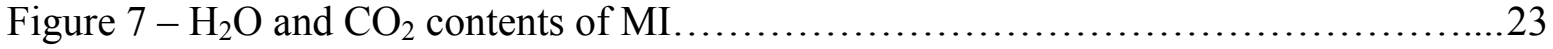

Figure 8 - A comparison of predicted and measured percent of total $\mathrm{CO}_{2}$ contained in the bubble based on analyses of similar MI...................... 27

Figure 9 - A comparison of reconstructed $\mathrm{CO}_{2}$ concentrations calculated using the Ideal Gas Law, an empirically-derived equation of state, and in situ Raman

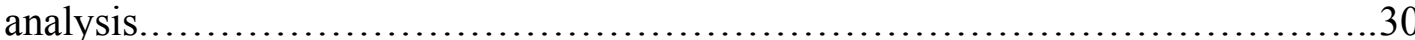




\section{List of Tables}

Table 1 - Sources of MI data....................................... 40

Table 2 - Petrographic and Raman spectral data for MI from Kilauea iki and Kapoho...... 41

Table 3 - Petrographic and Raman spectral data for MI from Fuego................... 46

Table 4 - Petrographic and Raman spectral data for MI from Seguam...................48

Table 5 - Reconstructed $\mathrm{CO}_{2}$ values and calculated pressures.......................50

Table 6 - Major element and volatile chemistry of Fuego and Seguam melt inclusions (corrected for PEC) ........................................... 51 


\section{INTRODUCTION}

It is well known that volatile contents and magma degassing behavior affect the style, frequency, and intensity of near-surface magmatic and volcanic processes (Sparks, 1978; Burnham and Ohmoto, 1980; Webster et al., 2001; Metrich and Wallace, 2008; and references therein). For this reason, much effort has been devoted to characterizing the volatile evolution of shallow magmatic (volcanic) systems to better constrain volcanic processes. Unfortunately, bulk rock or volcanic glass samples rarely reflect the pre-eruptive volatile content of a melt because the volatiles are lost from the system as the pressure decreases (Stolper \& Holloway, 1988; Dixon et al., 1995) when magma approaches the surface and erupts.

Melt inclusions (MI) are droplets of melt trapped as defects in a growing crystal, often as a result of varying crystal growth rates (Roedder, 1979; 1984; Metrich and Wallace, 2008). MI represent samples of melt that were isolated from the bulk magma at depth, thus preserving the composition of the pre-eruptive material (Roedder, 1979). For this reason, MI are particularly useful for determining pre-eruptive volatile budgets of volcanic systems, and MI are now routinely used to study a wide variety of volcanic and intrusive igneous processes (Roedder, 1979; Anderson et al., 2000; Hauri et al., 2002; Lowenstern, 2003; Wallace, 2005; Bodnar and Student, 2006; Gazel et al., 2012).

The analysis and interpretation of MI can be challenging because MI may experience post-entrapment modifications between the time of trapping, later eruption onto the surface, and analysis in the laboratory (Roedder, 1979; 1984). In particular, diffusion of $\mathrm{H}^{+}$through the host resulting in loss of $\mathrm{H}_{2} \mathrm{O}$ (Massare et al., 2002; Severs et al., 2007; Gaetani et al, 2012; Bucholz et al., 2013), and post-entrapment crystallization (PEC) (Danyushevsky et al., 2002; SteeleMacInnis et al., 2011) can affect the composition of the melt (glass) in the MI. These combined effects can produce misleading trends in the $\mathrm{H}_{2} \mathrm{O}-\mathrm{CO}_{2}$ content of the glass phase that are similar to those produced as a result of magma degassing (Gaetani et al., 2012; Steele-MacInnis et al., 2011; Bucholz et al., 2013).

The formation of a bubble in a MI after trapping is a natural consequence of the PVTX properties of crystal-melt-volatile systems (Lowenstern, 1995). Following entrapment, as the host phenocryst and its contained MI cool, the volume occupied by the melt will decrease more (a larger percentage) than that of the host phenocryst owing to their different thermal expansion 
properties, i.e., silicate liquids are more susceptible to thermal expansion than solids. Further volume reduction is caused by PEC because the molar volume of the mineral precipitated on the MI wall, olivine for example, is less than the partial molar volume of that component (i.e., the "olivine" component) in the melt phase. If melts do not remain metastable, or "stretched" (Lowenstern, 1995) during initial cooling, a void (bubble) forms in the MI as a necessary consequence of these processes (Roedder, 1979; 1984). If the melt is volatile-free, the void (bubble) is essentially a vacuum. However, if the melt contains volatiles such as $\mathrm{H}_{2} \mathrm{O}, \mathrm{CO}_{2}$, and $\mathrm{S}$, that become less soluble with decreasing pressure (Dixon et al., 1995), the decrease in pressure associated with melt contraction would necessarily lead to the exsolution of some of the volatile component from the melt and into the vapor bubble. Thus, formation of a vapor bubble could deplete the melt in some, or most, of its volatiles.

Previous workers have recognized that bubble formation is an obstacle which affects the interpretation of MI trapping conditions based only on analysis of the glass phase. Approaches to address and/or correct for the presence of bubbles in MI vary. Some workers have avoided or limited the use of MI that contain bubbles (Lowenstern, 1994; Wallace and Gerlach, 1994; Wallace et al., 1999; Helo et al., 2011; Esposito et al., 2011; Lloyd et al., 2013). When only bubble-bearing MI were available for study, some workers have acknowledged potential contributions from the bubble by stating that the $\mathrm{CO}_{2}$ contents and pressures determined from the MI are minimum values (Anderson and Brown, 1993; Cervantes and Wallace, 2003; Spilliaert et al., 2006; Kamenetsky et al., 2007; Johnson et al., 2008; Vigouroux et al., 2008; Ruscitto et al., 2010; Esposito et al., 2011). Others report that bubbles are present, but do not further discuss their potential contribution to MI volatile abundances (Lowenstern, 1994; Roggensack et al., 1997; Walker, 2003; Liu et al., 2006; Mangiacapra et al., 2008; Lloyd et al., 2013). Schipper et al. (2010) argue that, based on a positive correlation between $\mathrm{CO}_{2}, \mathrm{H}_{2} \mathrm{O}$, and $\mathrm{MgO}$ in their highFe MI, the bubbles in these MI were likely either trapped heterogeneously or only contain a vacuum and should be ignored in either case. We note, however, that it is not possible for a volatile-bearing MI to contain a shrinkage bubble that contains no mass (i.e., contains none of the volatiles that were originally dissolved in the melt). For this to occur, at the moment that the shrinkage bubble forms in the MI, the pressure in the shrinkage bubble would be a vacuum $(\sim 0$ $\mathrm{MPa}$ ) while the immediately adjacent melt would be at some much higher pressure, and this pressure "gradient" or "discontinuity" would have to be maintained during continued cooling - 
an impossible scenario. Thus, any bubble contained in a volatile-bearing MI must also contain some volatiles.

\section{Pseudo degassing paths}

It is possible generate a suite of MI with a range in volatile contents in the glass without any variation in the composition of the melt that was originally trapped. This is possible through mass transfer of volatiles from the melt to bubble after trapping. To demonstrate this principle, we have calculated the trend in $\mathrm{H}_{2} \mathrm{O}-\mathrm{CO}_{2}$ contents that would be generated if a suite of inclusions are all trapped at the same temperature and pressure, and all trap a melt containing $1200 \mathrm{ppm}$ $\mathrm{CO}_{2}$. Then, following trapping, vapor bubbles having various sizes ( 0.5 to 2.0 volume percent of the MI) and densities of $\mathrm{CO}_{2}$ vapor $\left(0.04\right.$ to $\left.0.16 \mathrm{~g} / \mathrm{cm}^{3}\right)$ form in the MI. Variable bubble size and fluid density might be expected to result when a group of MI that were all trapped at the same time are erupted and cool quickly, with the actual amount of time to cool to below the glass transition temperature a function of the clast and/or phenocryst grain size, and depth of burial in the eruptive sequence. Under these conditions, we might expect that inclusions with different sizes and in different crystals might exsolve varying amount of volatiles from the melt into the growing vapor bubbles, producing a range of bubble sizes and fluid densities.

The trend that might be produced from this suite of MI that all contain the same total amount of $\mathrm{CO}_{2}$ (Figure 1) is similar to trends produced as a result of open-system degassing (e.g., Lowenstern, 1994; Walker, 2003). If the $\mathrm{CO}_{2}$ contained in the bubbles in this scenario were then "added back in" to the melt, the reconstructed $\mathrm{CO}_{2}$ concentration would be the same for every inclusion (here, $1200 \mathrm{ppm}$ ). Note that we assume that the concentration of $\mathrm{H}_{2} \mathrm{O}$ in the melt does not change for this calculation (Figure 1, symbols are slightly offset so they can be viewed easily). This assumption is appropriate for low $-\mathrm{H}_{2} \mathrm{O}$ melts such as those trapped in MI from Kilauea. Low $\mathrm{H}_{2} \mathrm{O}$ contents in vapor bubbles are also reported in calculations by Shaw et al. (2008) and measurements by Wallace et al. (in review). However, for melts that contain higher concentrations of $\mathrm{H}_{2} \mathrm{O}$ (like Fuego or Seguam), it remains possible that a significant portion of the $\mathrm{H}_{2} \mathrm{O}$ in the melt may exsolve as pressure decreases to less than about 1000 bars, thus changing the $\mathrm{H}_{2} \mathrm{O}$ content of the remaining melt (glass). Thus, this simple calculation illustrates the importance of quantifying the amount of $\mathrm{CO}_{2}$ contained in the bubble. 


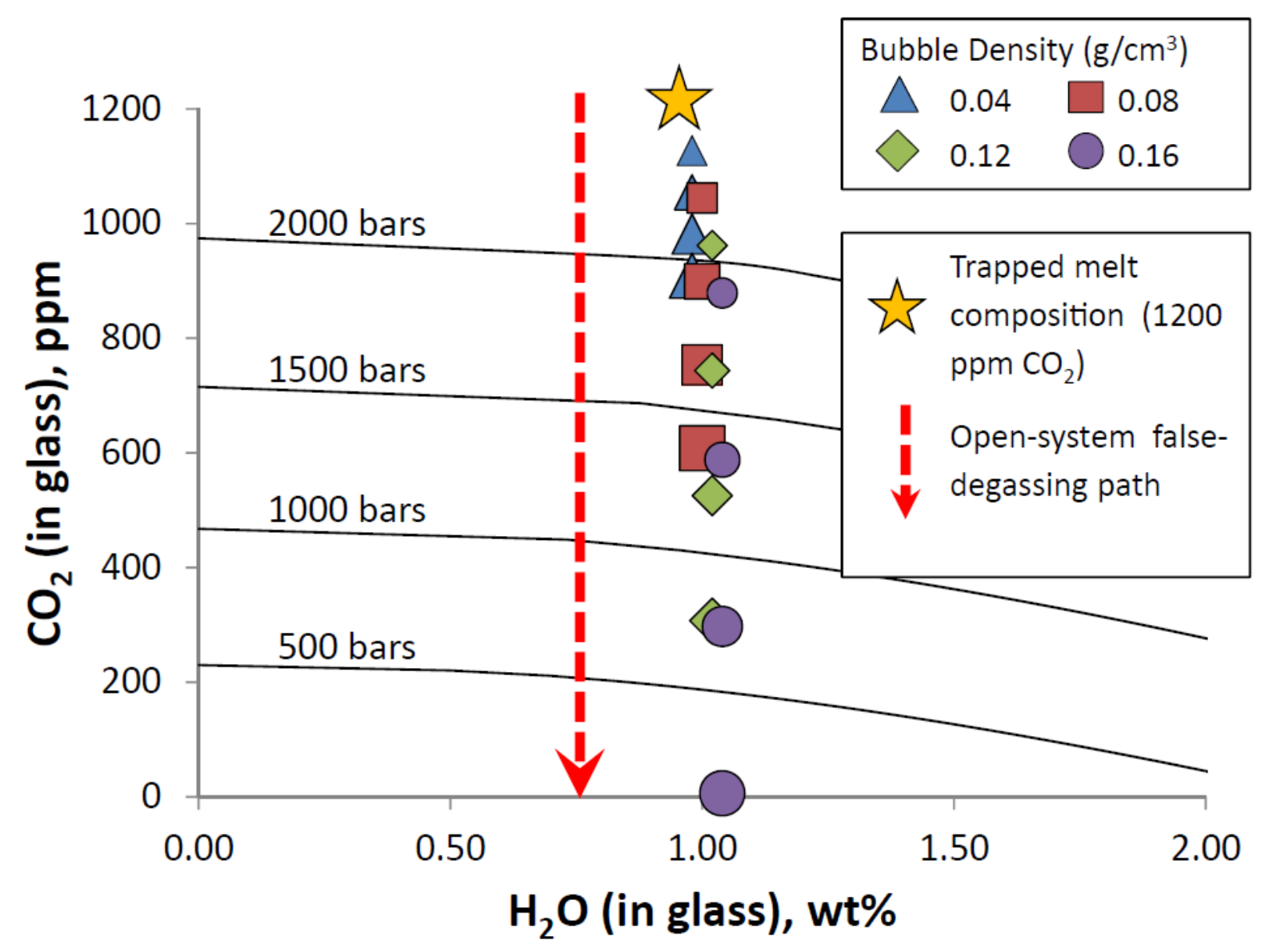

\section{Figure 1}

A "false" degassing path calculated for a group of MI that all trapped a melt containing 1200 ppm CO2. The symbols represent the $\mathrm{CO} 2$ content of the glass phase in MI that formed vapor bubbles of various sizes (0.5-2.0 volume percent; symbol size is proportional to bubble volume percent) and densities (indicated by different symbol shapes; 0.04-0.16 g/cm3). The false degassing path is indistinguishable from a true degassing path. Isobars were calculated for a basaltic melt using VolatileCalc (Newman and Lowenstern, 2002).

\section{Quantifying the $\mathrm{CO}_{2}$ in $\mathrm{MI}$ vapor bubbles}

Some workers have recognized that vapor bubbles contain some of the volatiles that were originally dissolved in the melt and have attempted to quantify the contribution of the vapor bubble to the total volatile budget. For example, Anderson and Brown (1993) estimated the amount of $\mathrm{CO}_{2}$ contained in the vapor bubbles of a suite of MI from Kilauea by estimating the change in volume of the bubble associated with changes in temperature and pressure during cooling. Cervantes et al. (2002) homogenized MI from a Mauna Loa picrite and found that $~ 80 \%$ of the $\mathrm{CO}_{2}$ in the $\mathrm{MI}$ had been lost to the bubble during post-entrapment cooling (Wallace et al, in review). Shaw et al. (2008) obtained a similar result for a suite of Mariana Arc MI by 
measuring the $\mathrm{H}_{2} \mathrm{O}$ and $\mathrm{CO}_{2}$ concentrations in the glass and then using the Ideal Gas Law (IGL) to calculate the amount of $\mathrm{CO}_{2}$ in the bubble (see below). Esposito et al. (2011) measured the density of $\mathrm{CO}_{2}$ in a vapor bubble in a MI from the Solchiaro eruption at Procida Island, Italy, using Raman spectroscopy, and determined the concentration of $\mathrm{CO}_{2}$ in the glass using secondary ion mass spectrometry (SIMS). Mass balance reconstruction (using a method described by Steele-MacInnis et al., 2011) of the bulk composition of the trapped melt revealed that the vapor bubble contained $\sim 64 \%$ of the total $\mathrm{CO}_{2}$ in the MI. Using a similar approach, Hartley et al. (2014) reconstructed the compositions of a suite of MI from the 1783-1784 Laki eruption in Iceland.

Raman analysis provides a fast, simple, and non-destructive method to determine the density of $\mathrm{CO}_{2}$. Kawakami et al. (2003) found that the density of $\mathrm{CO}_{2}$ is related to the distance between two Raman lines (collectively referred to as the Fermi diad) (Figure 2). Fall et al. (2011) extended and modified the densimeter and applied it to determine salinities of $\mathrm{CO}_{2}$-bearing fluid inclusions based on the clathrate melting temperatures and pressures estimated from the $\mathrm{CO}_{2}$ density.

In this study, we analyzed bubble-bearing MI from various locations to determine a complete volatile budget for the $\mathrm{MI}$ that includes both $\mathrm{CO}_{2}$ in the glass and in the bubble. We analyzed vapor bubbles in melt inclusions in olivine phenocrysts from Fuego volcano, Guatemala (1974 eruption), from Seguam Island, Alaska (1977 eruption), and from the summit and East Rift Zone of Kilauea, Hawaii (the 1959 Kilauea Iki and 1960 Kapoho eruptions, respectively). We used a combination of SIMS and Fourier transform infared spectroscopy (FTIR; Tuohy et al., in preparation) to determine the volatile content of the glass, and we used Raman spectroscopy to quantify the density of $\mathrm{CO}_{2}$ in the vapor phase. We then used a mass balance method (Steele-MacInnis et al., 2011) to reconstruct the total $\mathrm{CO}_{2}$ concentrations of MI and evaluate the implications of ignoring the contribution of the bubble to the MI volatile budget for predicting magma degassing behavior in volcanic systems. 


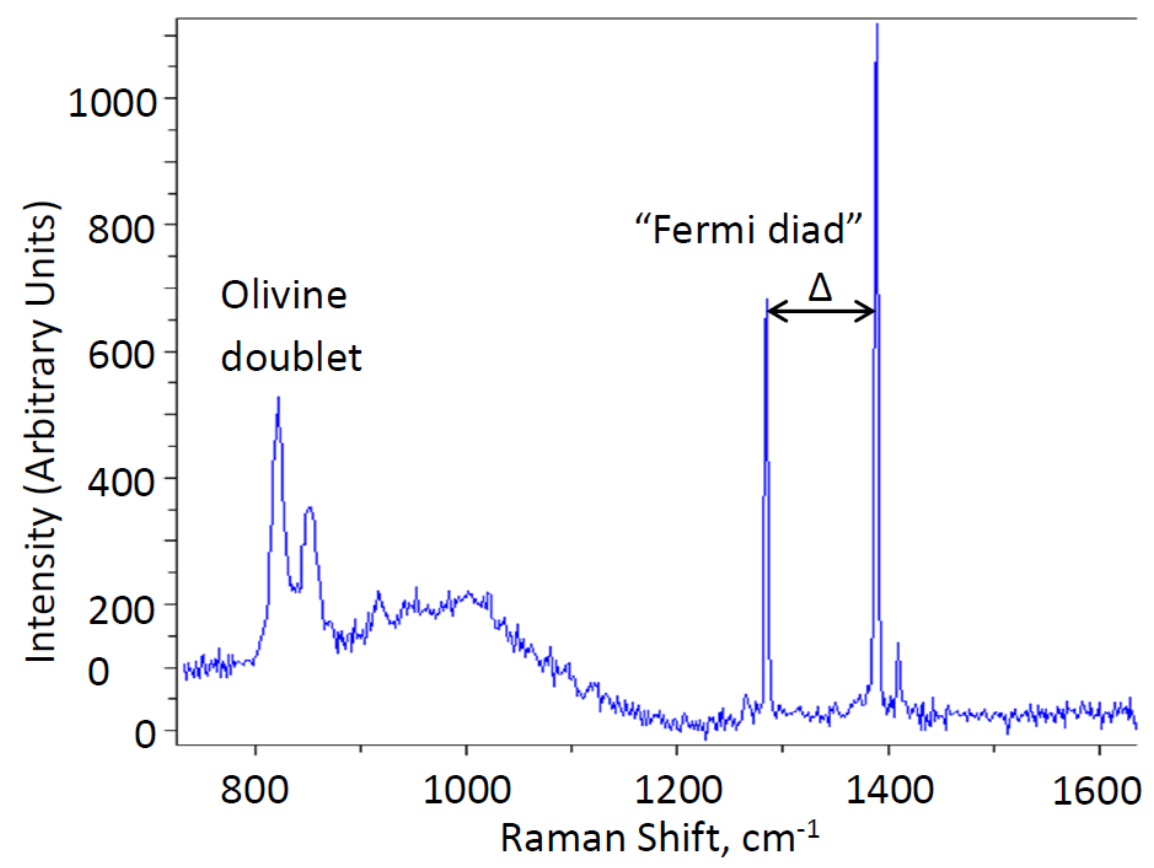

Figure 2

Raman spectrum of a vapor bubble in an olivine-hosted MI from the 1974 eruption of Fuego volcano (Table 3, Fuego 19.1). Peaks corresponding to the olivine host crystal and $\mathrm{CO}_{2}$ in the bubble (the Fermi diad) are labeled. The density of $\mathrm{CO}_{2}$ in the bubble is related to the distance between the two peaks in the Fermi diad $\left(\Delta, \mathrm{cm}^{-1}\right)$, and was calculated using the equation of Fall et al. (2011). 


\section{METHODS}

\section{Sample collection and preparation}

The MI analyzed in this study were contained in tephras that have been used in other previous studies (listed below). We did not analyze the same inclusions in these studies, but the MI analyzed in this study were contained in olivines that were separated from the same bulk tephra samples that were used by other workers. The tephras come from Kilauea (Hawaii), Fuego volcano (Guatemala), and Seguam Island (Alaska). The tephras from Kilauea were erupted during the 1959 Iki and 1960 Kapoho eruptions (Richter et al., 1970) and olivine separates were prepared as described by Tuohy et al. (in preparation, Samples Kil Iki Nat R, and Kap 8 Nat R). Olivine phenocrysts from Fuego volcano were from a population of samples collected during the October 1974 eruption by Rose et al. (1978), and the olivine phenocrysts were separated as described by Lloyd et al. (2013) (sample VF-74-131). Tephras from Seguam Island were erupted during the 1977 eruption of Pyre Peak (Jicha et al., 2006). The samples were collected and

olivine separates were prepared as described by Zimmer et al. (2010; sample SEG07-06). A summary of the various methods used in this and previous studies to analyze the MI described below is given in Table 1.

The olivine phenocrysts from Kilauea were mounted individually in Crystalbond ${ }^{\mathrm{TM}}$ on glass slides and polished. Olivine phenocrysts from both Fuego and Seguam were also mounted individually by attaching each crystal to the end of a $2.5 \mathrm{~mm}$ diameter glass rod using Crystalbond ${ }^{\mathrm{TM}}$ and polished following the methodology described by Thomas \& Bodnar (2002). MI were polished on an abrasive pad ( $3 \mu \mathrm{m}$ diamond suspension) until they were sufficiently close to the surface of the crystal for Raman analysis and were then finished with a $0.3 \mu \mathrm{m}$ alumina suspension. Individual crystals were mounted and polished to allow greater control over the amount of host material surrounding the MI that was removed during polishing to assure that none of the vapor bubbles would be breached during sample preparation.

The MI from Kilauea Iki and Kapoho (Figure 3a,b) are generally smooth-walled, clear, and round to subhedral (negative crystal shape). Eighty percent of the MI contain a vapor bubble that occupies between $\sim 1$ and 10 volume percent of the inclusion (Table 2). Some of the MI also contain a small ( $\leq 1$ volume percent) opaque daughter crystal of chromite, and a few of the inclusions contain larger (10's of volume percent) chromite crystals that were likely co-trapped 

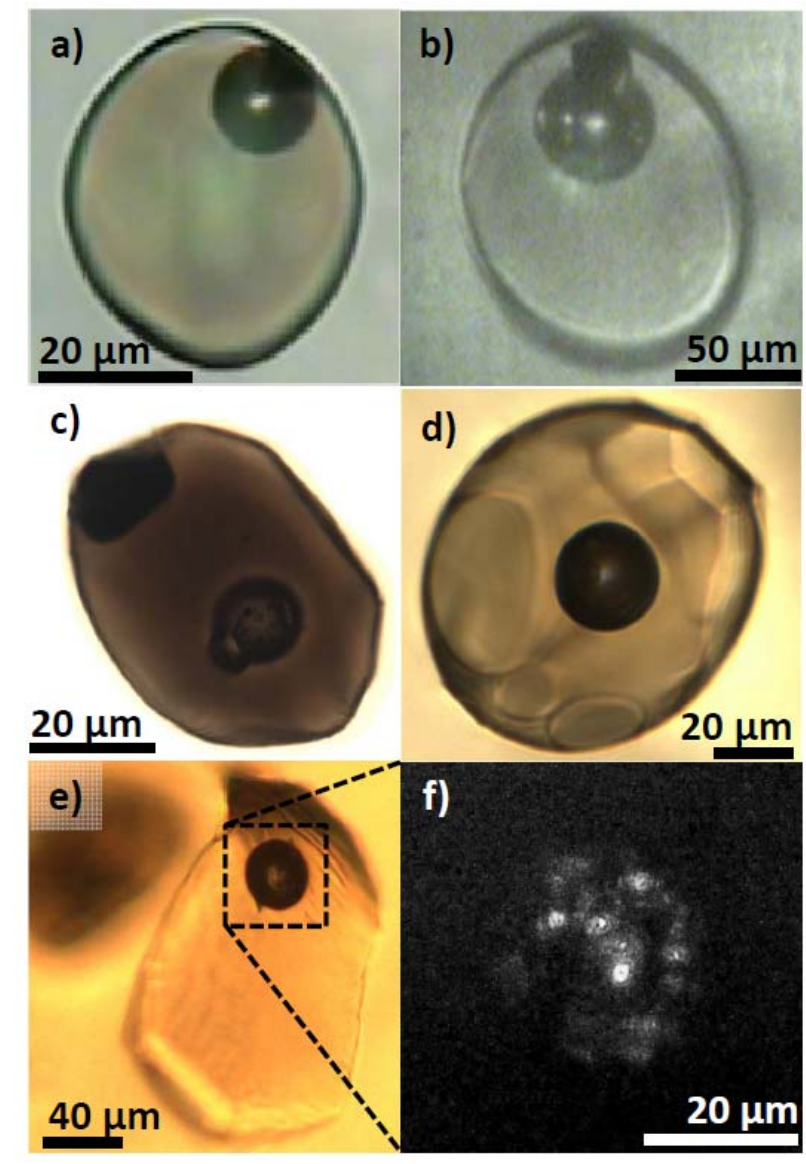

\section{Figure 3}

Previous page. Photomicrographs of representative MI. (a) a typical glassy MI (Kil Iki Nat R 3_10) hosted by an olivine phenocryst from tephra erupted by Kilauea Iki (1959 eruption). (b) a typical glassy MI (Kap 8 Nat R 5_3) hosted by the phenocryst from tephra erupted by Kapoho (1960 eruption) shown in transmitted light. Some of the MI from Kilauea Iki and Kapoho contain opaque daughter spinels (?) as shown in (b). (c) a medium brown MI from the 1976 eruption of Fuego Volcano, Guatemala that contains a spinel (?) daughter mineral and a single vapor bubble (Table 3, Fuego MI 11.1) with visible carbonate daughter minerals at the bubble/glass interface (see text). (d) a typical glassy, bubble-bearing MI (Seguam 14.1) hosted by an olivine phenocryst prepared from tephras erupted on Pyre Peak (1977), Seguam Island, Alaska. This MI shows the typical "wrinkled" texture common in the larger MI ( 100 $\mu \mathrm{m}$ or larger) from these samples. (e-f) An olivine-hosted MI from Seguam Island, Alaska (SEG 7.1) that contains carbonate daughter minerals that have formed at the bubble-glass interface. (e) a photomicrograph of the MI in transmitted light showing the location of the vapor bubble. (f) a photomicrograph of the bubble from (e) in reflected light; the image contrast is enhanced for greater visibility of carbonate minerals. Carbonate was detected during Raman analysis of the bubble, and we suspect that the bright texture visible in reflected light is due to the scattering of light by carbonate minerals. The carbonate daughter minerals could contain a significant amount of $\mathrm{C}$ that is not quantified in our study (see text). 
with the melt. The olivine host also contains many chromite inclusions, as well as clusters of chromite with small amounts of interstitial melt. Chromite is a common phase in olivine-hosted MI from Kilauea (e.g., Anderson and Brown, 1993).

The MI from Fuego volcano are round to euhedral (negative crystal shape), with walls that have a smooth to wrinkled texture (Fig 2c). Most of the MI contain a single vapor bubble. The vapor bubbles range from $\sim 1-5$ volume percent of the MI (Table 3). Some of the MI also contain blocky, opaque daughter crystals ( $<1-5$ volume percent), and some of these have filiform microcrysts radiating from them. These daughter minerals could have grown rapidly due to undercooling of the MI (Roedder, 1979), and if the crystals represent anhydrous phases the melt (glass) would be enriched in volatiles (relative to the melt that was originally trapped in the MI) as a result of this post-entrapment crystallization.

The MI from Seguam (Fig. 2d) are more uniform in color and texture compared to those from Kilauea and Fuego. The inclusions are all essentially clear, tan, and bubble-bearing. All of the larger $(>\sim 50 \mu \mathrm{m})$ inclusions have a wrinkled texture. The bubbles occupy between $<1$ and 6 volume percent of the MI.

MI from all three sample suites were examined on a petrographic microscope and photographed. The images were analyzed using image analysis software (ImageJ and LabSpec) to determine the MI dimensions. The vapor bubbles were approximately spherical and the volumes could thus be estimated from the measured diameter. Most of the MI were oblate in shape and the long and short axes were measured and the volume was approximated as an oblate spheroid.

Before conducting Raman analysis, each MI was examined to distinguish between those that trapped bubbles along with the melt, and those that trapped only melt and nucleated a vapor bubble in the MI after trapping. If the vapor bubbles represent volatiles that were originally dissolved in the trapped melt and then exsolved from the melt after trapping, we should expect a correlation between MI size (volume) and vapor bubble size (volume) (Roedder, 1984). Thus, larger inclusions should have proportionally larger vapor bubbles, assuming that all MI exsolve a similar proportion of the volatiles that were originally dissolved in the melt. Conversely, if the MI trapped a melt plus a vapor bubble, we would expect to see a large range ( $>10$ volume percent) in relative vapor bubble sizes in the population of MI sampled. We compared MI bubble volume percents by plotting the MI volume against bubble volume for all MI in each eruption to determine whether the volumes exhibit a linear relationship (constant volume percent vapor). In 
addition to excluding groups of MI that display a large range in bubble volume percent, we exclude MI containing anomalously large bubbles (>10 volume percent) from our calculations because the bubbles were likely trapped as a separate phase or indicate that the MI leaked and depressurized after trapping.

\section{Raman analysis}

Developing a protocol for precise and accurate Raman analyses of MI - as opposed to synthetic fluid inclusions (FI) - was one of the objectives of this study. As such, the technique was improved as data was collected. Below, the conditions used in this study are reported followed by recommendations for the conditions to be used in future studies.

Raman spectra were collected using a JY Horiba LabRam HR (800 mm) Raman spectrometer equipped with a $100 \mathrm{~mW} 514 \mathrm{~nm}$ argon laser, confocal hole diameter of $400 \mu \mathrm{m}$,

$600 \mathrm{~mm}^{-1}$ and $1800 \mathrm{~mm}^{-1}$ gratings, and slit width of $150 \mu \mathrm{m}$. Three 30 -s scans were collected and averaged. GRAMS/AI and LabSpec software were used to apply a baseline correction to each spectrum and to fit the $\mathrm{CO}_{2}$ peaks using a mixed Gaussian/Lorentzian method. During every analytical session, the $\mathrm{CO}_{2}$ bubble in a synthetic $\mathrm{H}_{2} \mathrm{O}-\mathrm{CO}_{2}$ fluid inclusion (Sterner \& Bodnar, 1984) was analyzed to test for reproducibility in determination of the splitting of the Fermi diad.

Following peak fitting, the distance between the two peaks of the Fermi diad (peak splitting) was determined and the density was calculated from the peak splitting using the equation of Fall et al. (2011). While $\mathrm{CO}_{2}$ was detected in a large number of the vapor bubbles, as evidenced by the presence of the Fermi diad, the density of the $\mathrm{CO}_{2}$ could not be determined for all cases where the Fermi diad was observed. In some cases, the Fermi diad splitting $\left(\Delta, \mathrm{cm}^{-1}\right)$ was outside of the range over which the equation of Fall et al. (2011) is valid - usually this applied to bubbles with very low $\mathrm{CO}_{2}$ density. In other cases, the spectra were of poor quality with low peak intensities, and thus did not allow precise determination of peak positions and calculation of the Fermi diad splitting. For these inclusions, we noted that $\mathrm{CO}_{2}$ was detected but the density could not be quantified. Finally, it should be emphasized that failure to identify $\mathrm{CO}_{2}$ in a given MI during Raman analysis does not necessarily mean that $\mathrm{CO}_{2}$ is not present. The ability to detect a given species by Raman is a function of many factors, including but not limited to concentration (or number of moles) of the species in the analytical volume, depth of the feature beneath the mineral surface, shape of the MI-host interface (which affects light 
transmission), fluorescence from the host and/or glues used to mount the sample, etc (Burke, 1994; Burruss, 2003; Frezzotti, 2012).

For future analyses, we recommend that Raman spectra should only be collected using an $1800 \mathrm{~mm}^{-1}$ grating. A $600 \mathrm{~mm}^{-1}$ grating is useful because it provides a means to rapidly collect spectral data from a wider range of wavenumbers. This allows for a fast qualitative evaluation of both the quality of the spectra in general and a determination of what phases are present (e.g. carbonates, $\mathrm{CO}_{2}$, other phases within the $\mathrm{MI}$ ). However the resolution of the $600 \mathrm{~mm}^{-1}$ grating is insufficient for precise determination of peak positions in MI vapor bubbles. For example, some of the calculated $\mathrm{CO}_{2}$ densities that we observed using at this resolution exceeded the range of possible isochores for $\mathrm{CO}_{2}$ at room temperature or frequently produced other impossible densities $<0 \mathrm{~g} / \mathrm{cm}^{3}$.

In order to improve the precision of $\mathrm{CO}_{2}$ density calculations, instead of using the collection times reported here ( 3 collections for 30 seconds $=90$ seconds total), we recommend the use of longer collection times. The quality of the spectra increases dramatically as collection time increases, and a "point of diminishing returns" may exist for 5 collections for 30 seconds (150 seconds total). However, the optimal collection time will vary depending on the quality of the sample, the depth of the bubble within the phenocryst, and possibly the amount of $\mathrm{CO}_{2}$ in the bubble. Therefore, the optimal collection time should be determined for each suite of MI using one or a few "test MI" before $\mathrm{CO}_{2}$ density measurements are made.

It remains unclear whether it is better to fit peaks using GRAMS AI or LabSpec software. GRAMS AI produces more thorough peak-fitting reports with information on the error of the fit, the peak height, $\mathrm{R}^{2}$, and other measures of statistical uncertainty. However, based on repeated analyses of both synthetic FI and natural MI, it appears that the error reported by GRAMS AI may underestimate the reproducibility of the technique.

In order to quantify the reproducibility associated with density calculations we recommend continued measurements of a synthetic FI (as we have done) as well as repeated measurements of a MI from the suite of samples to be analyzed. Unfortunately, it was recently discovered that the synthetic FI used in this study contains a small amount of liquid $\mathrm{CO}_{2}$, and this likely has interfered with the fitting of the Fermi diad peaks as the peaks for liquid $\mathrm{CO}_{2}$ are very similar to those for $\mathrm{CO}_{2}$ vapor. This is likely because the synthetic FI that we have analyzed contains $\mathrm{CO}_{2}$ with the critical density, so both liquid and vapor $\mathrm{CO}_{2}$ are present in the inclusion 
at the temperature of the lab. Thus the uncertainty calculated for the density measurements reported here are likely overestimates.

\section{SIMS and EPMA analyses}

Following Raman analysis, samples were prepared for analysis of the glass in the MI. A subset of MI from Kilauea was analyzed by FTIR at the University of Oregon (Tuohy et al., in preparation), and a subset of MI from Seguam and Fuego was analyzed by SIMS at the Department of Terrestrial Magnetism of the Carnegie Institute of Washington (CIW). To prepare for SIMS analysis, the olivine phenocrysts were polished further (using the same method described above) until the glassy part of the target MI was exposed at the surface. After polishing, the fiberglass rod mounts were immersed in a series of acetone baths, each for a period of one minute, to completely dissolve the Crystalbond ${ }^{\mathrm{TM}}$ adhesive. The olivine phenocrysts were then pressed individually into a one-inch round indium mount in preparation for SIMS analysis.

Volatile contents of the MI glass were determined using a Cameca 6f secondary ion mass spectrometer at CIW. Samples were rastered over a $25 \mu \mathrm{m}$-wide spot using a 10-15 nA, $10 \mathrm{kV}$ $\mathrm{Cs}+$ ion beam; a $10 \mu \mathrm{m}$ aperture was used to restrict the analytical area to a $10 \mu \mathrm{m}$ spot. A more detailed description for the analytical technique used is given by Hauri (2002).

Following SIMS analysis, major elements were measured by electron probe microanalysis (EPMA) at Virginia Tech to obtain major element data that could be used to model the amount of PEC in the MI. The major element compositions of the MI glass and olivine host phenocrysts were measured using a Cameca SX-50 Electron Probe Microanalyzer. The glass and olivine host were analyzed with a $1 \mu \mathrm{m}$ beam and $15 \mathrm{kV}$ accelerating voltage. The olivine host was analyzed using a $21.9 \mathrm{nA}$ current, and the glasses were analyzed with a $9.9 \mathrm{nA}$ current.

Major element and volatile contents in the glassy part of the MI were corrected for PEC and Fe loss using Petrolog3 software (Danyushevsky \& Plechov, 2011). The calculations used the Borisov \& Shapkin (1990) model for melt oxidation state and assumed oxygen fugacity is buffered at Ni-NiO, and used the Lange \& Carmichael (1987) model for melt density and the Ford et al. (1983) olivine-melt model.

The concentration of $\mathrm{CO}_{2}$ in the melt that was originally trapped in the $\mathrm{MI}$ was estimated by combining the FTIR (Tuohy et al., in preparation) and SIMS data with the Raman data and applying the mass balance method described in Steele-MacInnis et al. (2011). For the MI from 
Kilauea that were too small and too numerous to analyze by FTIR, we assumed that the glass contained no $\mathrm{CO}_{2}$ when estimating the bulk (total) $\mathrm{CO}_{2}$ in the $\mathrm{MI}$ - this results in a minimum value for the melt that was originally trapped in the MI.

\section{Error Analysis}

In order to appropriately determine the error incurred by our mass balance calculations, each source of error must be considered individually and compounded through each calculation. The sources of error in these mass-balance calculations are 1) measurement of the density of $\mathrm{CO}_{2}$ in the bubble, 2) measurement of the concentration of $\mathrm{CO}_{2}$ in the glass, 3) measurement of the dimensions of the MI and bubble, 4) assumed density of the glass, and 5) the assumed orientation of the MI as viewed within the host phenocryst.

To quantify the error associated with the Raman technique for measuring the density of $\mathrm{CO}_{2}$ in the bubble, we conducted repeated measurements on a synthetic fluid inclusion bubble (Sterner \& Bodnar, 1984) with a known density of $\mathrm{CO}_{2}$ in the vapor phase. We made one measurement during each analytical session when analyzing MI so that our estimation of error would include both errors associated with calibrating the spectrometer and errors associated with peak fitting. Over 21 measurements, the relative standard deviation of these measurements was $19 \%(1 \sigma)$. We used this value for the error for all of our measured bubble densities.

The error associated with the SIMS analysis of the MI glass ranges from $1 \mathrm{ppm}$ to 46 ppm $(<1 \%$ to $9 \%)$, and was determined based on calibration curves generated using glass standards at CIW and the standard deviation during 5 repeated collections during five repeated analyses.

Because the bubble and MI dimensions were measured in visible light, $0.5 \mu \mathrm{m}$ is generally used as a minimum value for the precision of these measurements. The MI and bubble dimensions were clearly resolvable to within $1 \mu \mathrm{m}$ under the 100x objective, so we use this value $(0.5 \mu \mathrm{m})$ for the estimation of MI diameters. With this amount of error, the relative uncertainty for the volume calculation for a sphere increases exponentially with decreasing volume: from about $5 \%$ error for a $30 \mu \mathrm{m}$ bubble to $30 \%$ error for a $5 \mu \mathrm{m}$ bubble.

We assume that the bulk density of the glass is $2.75 \mathrm{~g} / \mathrm{cm}^{3}$. In order to determine the error that could be associated with this assumption, the relationship between glass bulk density and percent of total $\mathrm{CO}_{2}$ in the bubble is shown for various concentrations of $\mathrm{CO}_{2}$ in the glass in 
Figure 4. In general, our calculations become more sensitive to the bulk glass density as the contribution of the bubble to total $\mathrm{CO}_{2}$ decreases and as the concentration of $\mathrm{CO}_{2}$ in the glass increases. However, for the likely range in glass bulk density for mafic to intermediate melts (2.5 $-3.0 \mathrm{~g} / \mathrm{cm}^{3}$ ) and for the $\mathrm{CO}_{2}$ concentrations that we have observed by SIMS analysis, the relative error associated with glass bulk density is unlikely to exceed about $10 \%$.

When observing the MI in transmitted light, they appear to be oblate, and we can measure the long and short axis, but it is difficult to determine the depth of the MI, even by moving the stage. When calculating the volume of the MI, we assume that the depth of the MI is equal to the shorter diameter. To determine the range in error associated with the orientation of the MI, we assume that the third dimension of the MI (the depth when viewed through the microscope) could potentially be as long as the longest axis. If this were the case, the relative error would increase with increasing aspect ratio (long axis divided by short axis). For most of our inclusions, the source of error would not exceed about $10 \%$ to $50 \%$

We compounded the errors of our calculations individually by reconstructing the $\mathrm{CO}_{2}$ content of the bubble in two cases: a case where the bubble contributes the minimum amount of $\mathrm{CO}_{2}$, and a case where the bubble contributes the maximum amount of $\mathrm{CO}_{2}$. We then calculated the range in reconstructed $\mathrm{CO}_{2}$ concentrations from these endmember values. In the case for a minimum bubble concentration, we used the smallest bubble diameter (measured diameter -0.5 $\mu \mathrm{m}$ error), the largest possible MI (measured diameters $+0.5 \mu \mathrm{m}$ error) where the depth of the inclusion was assumed equal to the longest measured diameter, the greatest possible bulk density $\left(3.0 \mathrm{~g} / \mathrm{cm}^{3}\right)$, the lowest possible bubble density (calculated density $-19 \%$ error), and the greatest possible concentration of $\mathrm{CO}_{2}$ in the bubble (measured value + error). For the case for maximum concentration due to the bubble, we did the opposite: we assumed a larger, denser bubble, a smaller, less dense, MI glass with a lower $\mathrm{CO}_{2}$ concentration in the glass. 


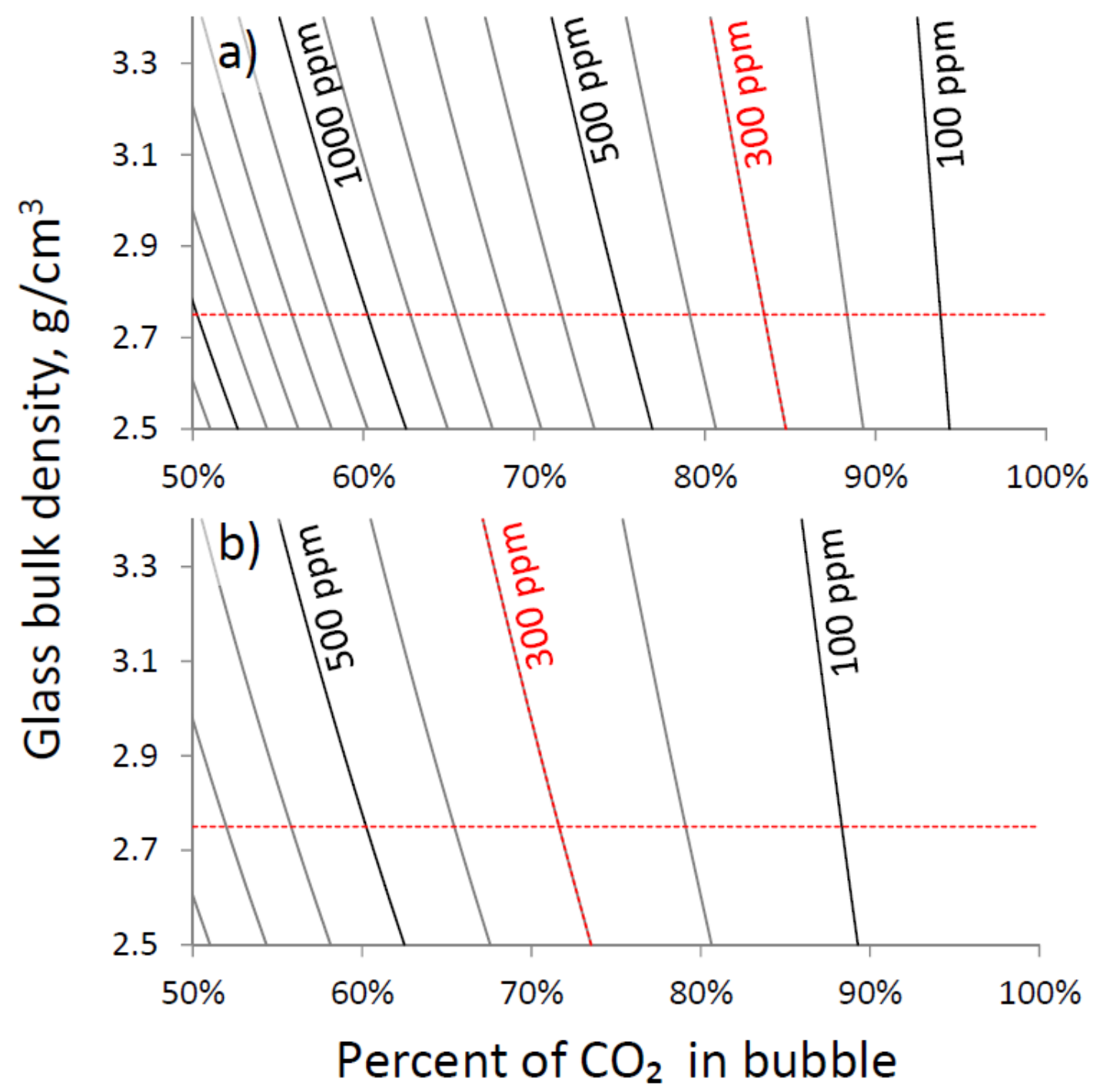

Figure 4

Calculated isopleths of glass $\mathrm{CO}_{2}$ concentration as a function of MI glass bulk density and bubble contribution (percentage of total $\mathrm{CO}_{2}$ contained in the bubble) with $\mathrm{CO}_{2}$ densities in the bubble of a) $0.1 \mathrm{~g} / \mathrm{cm}^{3}$ and b) $0.05 \mathrm{~g} / \mathrm{cm}^{3}$. These calculations were done assuming a typical bubble size (4 volume percent) and vapor density based on our measurements (Tables 2-4). The bulk density of the MI glass does not affect the reconstructed $\mathrm{CO}_{2}$ contents significantly, as shown by sub-vertical isobars. 


\section{RESULTS}

\section{Raman analyses}

Raman spectra of the bubbles in 148 MI from the Kilauea Iki and Kapoho (Hawaii) eruptions were collected: 75 MI from the Kilauea Iki eruption and 73 MI from the Kapoho eruption. $\mathrm{CO}_{2}$ was detected in 111 of the bubbles analyzed (i.e., the Fermi diad is clearly distinguishable), and the $\mathrm{CO}_{2}$ density could be quantified with reasonable precision in 98 of the bubbles analyzed. The density of $\mathrm{CO}_{2}$ in vapor bubbles in MI from both Kilauea Iki and Kapoho ranges from $<0.01$ to $0.29 \mathrm{~g} / \mathrm{cm}^{3}$. During Raman analysis, carbonate minerals were also detected (as evidenced by a peak at $1090 \mathrm{~cm}^{-1}$ in the Raman spectra) in four of the fifteen bubble-bearing MI from a phenocryst associated with the Kapoho eruption (sample Kap 8 Nat R 2). These carbonate phases could represent the product of reaction between $\mathrm{CO}_{2}$ that exsolved from the melt after trapping and the still hot melt or glass in the MI (Andersen et al., 1984). Alternatively, carbonate minerals could have precipitated directly from the $\mathrm{CO}_{2}$-rich fluid contained in vapor bubbles (Kamenetsky et al., 2002). However, given the relatively low density of the fluid and the small size of the bubble, the total number of moles of carbonate that could precipitate from the fluid would be very small and the resulting crystals would likely be too small to detect during Raman analysis, so we discount this possible mechanism.

Raman spectra were obtained from bubbles in $35 \mathrm{MI}$ from Fuego. $\mathrm{CO}_{2}$ was detected in 12 of the bubbles and could be quantified with reasonable precision in 10 of the bubbles. The density of $\mathrm{CO}_{2}$ in the bubbles ranges from 0.07 to $0.26 \mathrm{~g} / \mathrm{cm}^{3}$. Carbonates were also detected during analysis of 16 of the 35 vapor bubbles (Table 3 ).

We collected Raman spectra from 48 bubbles in MI from Seguam. We detected $\mathrm{CO}_{2}$ in 19 of these bubbles, and the density could be quantified with reasonable precision in 13 bubbles. The bubble densities range from 0.01 to $0.07 \mathrm{~g} / \mathrm{cm}^{3}$. No daughter minerals (or co-trapped) phases were observed in MI from Seguam, with the exception of carbonates at the bubble-glass interface (Table 4). Figure 3e,f shows a texture that we associate with the presence of carbonates. This texture is commonly visible when viewing bubbles in MI from Seguam in reflected light. During Raman analysis of the bubble shown in Figure 3e, carbonates were not detected until the analytical spot was positioned over the bright spot shown near the center of Figure 3f. In Table 4, we record the presence of the carbonate mineral texture and the presence of a carbonate peak in the Raman spectra separately, but we consider both to indicate the presence of carbonates. 


\section{Volumetric analysis of MI}

Densities of $\mathrm{CO}_{2}$ in the vapor bubbles obtained from Raman analysis may be used to determine the amount of $\mathrm{CO}_{2}$ contained in the bubble, which may then be used to reconstruct the original $\mathrm{CO}_{2}$ content of the melt that was trapped by the MI. However, it is first necessary to confirm that the $\mathrm{CO}_{2}$ in the vapor bubbles was originally dissolved in the melt and subsequently exsolved from the melt after trapping.

If MI trapped various proportions of melt and vapor, we would expect a wide range in the relative size of the vapor bubbles in MI, whereas if the vapor bubbles exsolved from the melt after trapping we would expect to see a relative uniform vapor bubble to glass ratio in the MI (Roedder, 1984). To assess whether the vapor bubbles in MI were trapped along with melt, or were generated after trapping by volatile exsolution from the melt, the bubble and MI volumes were estimated as described above (see methods).

Each phenocryst from Kilauea contained multiple MI, allowing us to evaluate the relationship between MI volume and bubble volume for each phenocryst individually. The relationship between MI and vapor bubble size of two Kilauea Iki samples is shown for two phenocrysts in Figure 5a. Most inclusions in phenocryst Kil Iki Nat R 6 exhibit a linear relationship between MI volume and bubble volume. This indicates a constant volume percent vapor in the MI and suggests that the vapor bubbles represent volatiles that were originally dissolved in the melt at the time of trapping and which exsolved from the melt after it was isolated as a melt inclusion. However, several of the MI in phenocryst Kil Iki Nat R 4 have vapor bubbles that vary in volume over two orders of magnitude without a correlation to MI volume (i.e., the volume percent of the MI occupied by the vapor bubble is not constant). These MI are interpreted to have trapped various proportions of melt and vapor. Although it appears that only the smaller MI $\left(10^{-3} \mu^{3}\right)$ in this phenocryst trapped vapor as a separate phase, we exclude all of the MI hosted by phenocryst Kil Iki Nat R 6 from further calculations and discussion as a precaution.

Unlike the samples from Hawaii, the phenocrysts from Fuego and Seguam generally host fewer MI. MI in these samples do not contain anomalously large (>10 volume percent) vapor 


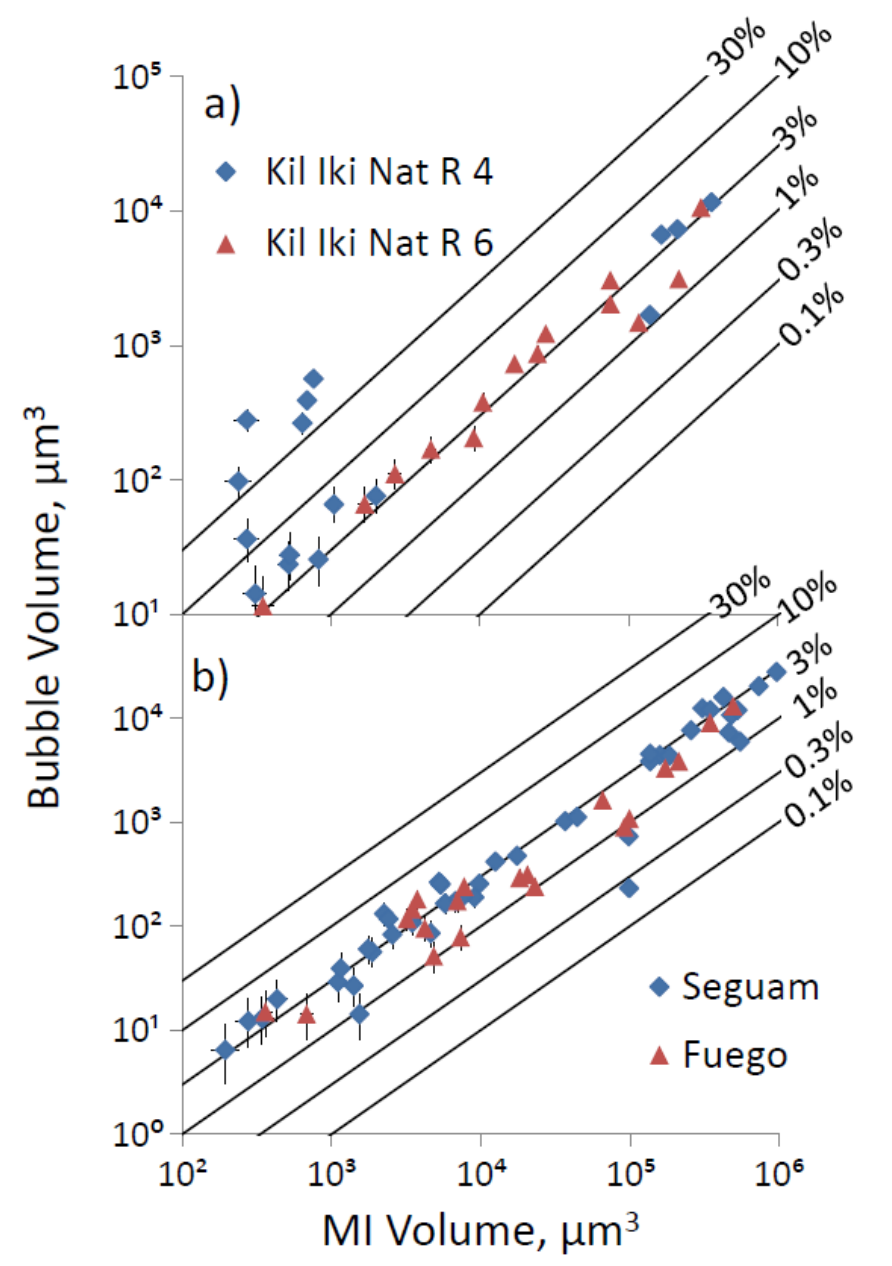

\section{Figure 5}

Plots show MI volume and bubble volume with contours of volume percent vapor for (a) two MI from Kilauea iki, and (b) MI from Seguam and Fuego (see text). A linear relationship between MI volume and bubble volume indicates that all MI contain the same volume percent vapor, and this suggests that the MI trapped only melt and that the bubbles were generated in the MI after trapping. One of the phenocrysts from Kilauea (Kil Iki Nat R 4) shows a more random relationship between $\mathrm{MI}$ and bubble size. This suggests that the $\mathrm{MI}$ in this phenocryst may have trapped a mixture of melt and vapor. The MI from this phenocryst were not used in any further calculations (see text). Bubble volumes were calculated as spheres, and MI volumes were calculated as oblate spheres using the measured long and short dimensions (see text).

bubbles that might suggest either heterogeneous trapping or reequilibration. For this reason, the volumetric properties for all Fuego and Seguam MI are plotted together in Figure 5b. Similar to the majority of the Kilauea MI, the vapor bubble volumes and MI volumes have a linear relationship ( $\sim 3$ volume percent) that suggests that the vapor bubbles were exsolved from the 
melt after trapping. Therefore, the volatile content of the MI (glass + bubble) is representative of the volatile content of the melt at the time of trapping.

\section{Reconstructing the original $\mathrm{CO}_{2}$ content of the trapped melt}

Using the information obtained from Raman analysis of the vapor bubbles in MI, combined with the volumetric proportions of vapor bubble and glass in the MI, the $\mathrm{CO}_{2}$ content of the trapped melt can be reconstructed using a mass balance approach (Steele-MacInnis et al., 2011). We consider two cases: one case in which the $\mathrm{CO}_{2}$ content of the glass is not known (Figure 6 and histograms shown in Figure 7), and one case in which the $\mathrm{CO}_{2}$ content of the glass is known (Figure 7). After reconstructing the $\mathrm{CO}_{2}$ content of the trapped melt we discuss what proportion of the total $\mathrm{CO}_{2}$ in the $\mathrm{MI}$ is contained in the vapor bubble, and implications for estimating depths of formation and degassing paths.

\section{The $\mathrm{CO}_{2}$ content of the glass in the $\mathrm{MI}$ is unknown}

In some studies, it may be possible to determine the $\mathrm{CO}_{2}$ density in the vapor bubble and the volumetric proportions of vapor and glass in the MI, but the volatile content of the glass phase is unknown. For example, while vapor bubbles as small as about 1 or $2 \mu \mathrm{m}$ in diameter can be analyzed by Raman, the glass phase in MI less than about 20 to $30 \mu \mathrm{m}$ in minimum dimension generally can not be analyzed by conventional SIMS or FTIR. For such MI, it is possible to estimate a minimum $\mathrm{CO}_{2}$ content of a $\mathrm{MI}$ using results from Raman spectroscopy only. This is particularly useful because most of the MI from Kilauea examined in this study were too small and too numerous to be analyzed by FTIR or SIMS and, thus, the $\mathrm{CO}_{2}$ content of the glass phase in these $\mathrm{MI}$ is unknown. For such $\mathrm{MI}$, a minimum $\mathrm{CO}_{2}$ content for the $\mathrm{MI}$ could be obtained by simply assuming that the glass conains no $\mathrm{CO}_{2}$ and then adding the $\mathrm{CO}_{2}$ in the bubble back into the glass, using the relative volume proportions of bubble and glass determined previously. This approach provides a minimum $\mathrm{CO}_{2}$ content for the reconstructed melt. The relative error associated with these calculations ranges from about $1 \%$ to $20 \%$, increasing with bubble density and volume percent vapor.

Alternatively, sometimes data are available for MI from the same eruption that can be used to approximate the $\mathrm{CO}_{2}$ content of the glass, as in the case of Kilauea MI studied here. As such, we estimated the percentage of total $\mathrm{CO}_{2}$ that might be contained in the bubbles of Kilauea MI by assuming that the glass phase in our MI is similar to MI from the same Kilauea Iki (0-250 
ppm, with one value of 425 ppm) and Kapoho (100-300 ppm) samples (Tuohy et al., in preparation). Kilauea Iki MI analyzed by Anderson and Brown (1993) have similar CO2 concentrations (0-300 ppm, with a single outlier above $700 \mathrm{ppm}$ ). Based on these values, we reconstruct the $\mathrm{CO}_{2}$ content of the original melt assuming two cases: first that the glass contains $0 \mathrm{ppm} \mathrm{CO}_{2}$ and second that the glass contains $300 \mathrm{ppm} \mathrm{CO}_{2}$.

We note that in the second case, the reconstructed $\mathrm{CO}_{2}$ content is $300 \mathrm{ppm}$ greater because of the simplifying assumption that the mass of the bubble is negligible compared to the mass of the glass phase. As a result, the reconstructed $\mathrm{CO}_{2}$ concentration can be determined for any known or assumed concentration of $\mathrm{CO}_{2}$ in the glass simply by adding the concentration of $\mathrm{CO}_{2}$ in the glass (in ppm or wt\%) to the reconstructed melt concentration calculated assuming that the glass contains no $\mathrm{CO}_{2}$. This assumption is valid for all of the bubble volumes and $\mathrm{CO}_{2}$ densities encountered in this study. For example, the most massive bubble we observed, MI Kap 8 Nat R 4_12 (Table 2) contains 9.5 percent vapor with a density of $0.14 \mathrm{~g} / \mathrm{cm}^{3}$. The reconstructed $\mathrm{CO}_{2}$ concentration of the melt assuming that the glass contains $0 \mathrm{ppm} \mathrm{CO}_{2}$ is 5385 $\mathrm{ppm}$. If however, the glass contains $300 \mathrm{ppm}$, then the reconstructed melt in this MI would contain $5683 \mathrm{ppm}$. Thus, the $\mathrm{MI}$ in which the glass contains $300 \mathrm{ppm} \mathrm{CO}_{2}$ has a reconstructed $\mathrm{CO}_{2}$ concentration that is $298 \mathrm{ppm}$ greater than the reconstructed 


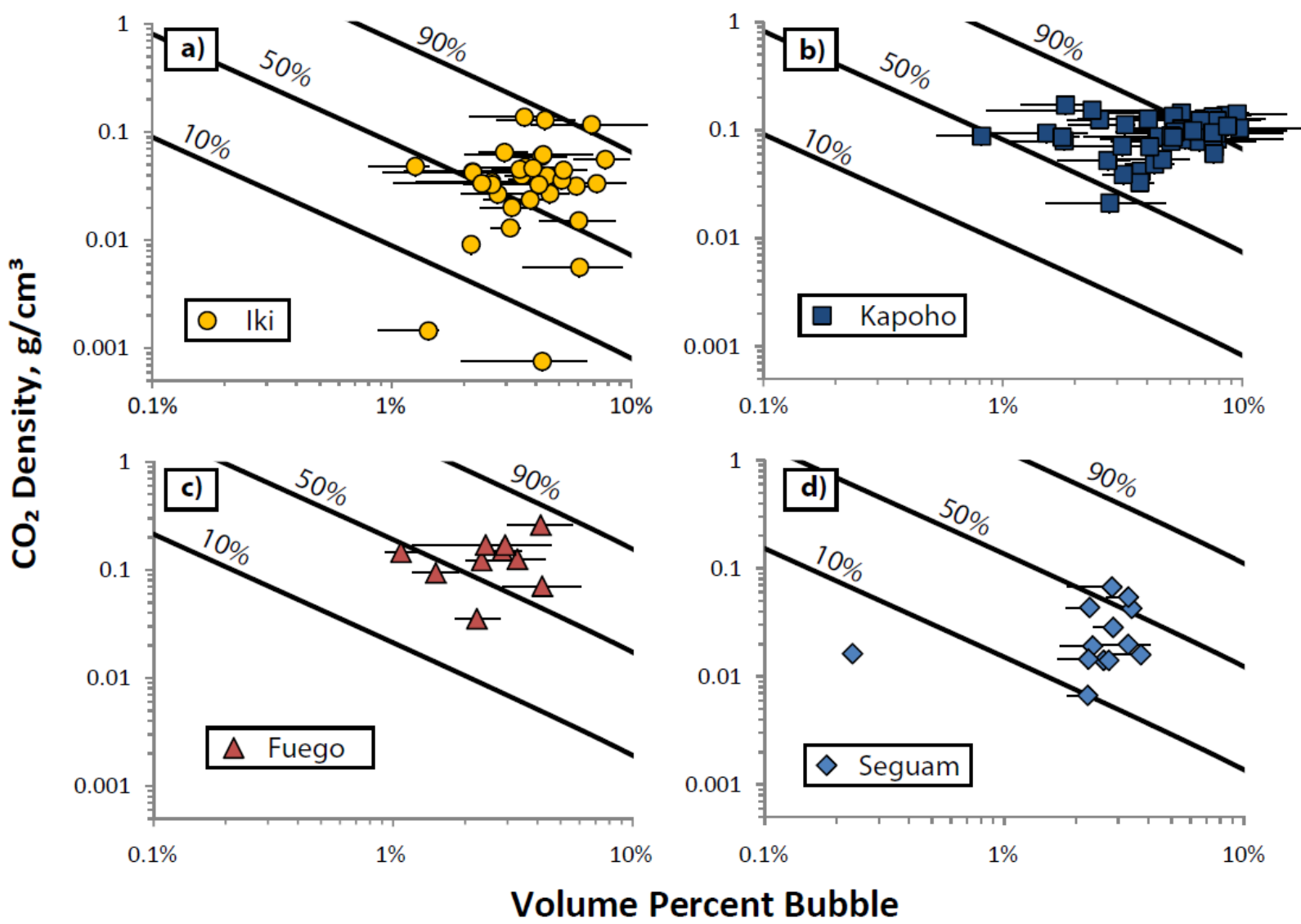

Figure 6

The density of $\mathrm{CO}_{2}$ contained in the bubbles of glassy MI is shown as a function of the volume percent bubble in MI from a) the 1959 Iki eruption at the summit of Kilauea (Hawaii), b) the 1960 Kapoho eruption on the East Rift Zone of Kilauea, c) the 1974 eruption of Fuego volcano (Guatemala), and d) the 1977 eruption of Seguam Island (Alaska). The contours show the percent of the total amount of $\mathrm{CO}_{2}$ in the MI that is contained in the bubble assuming a bulk glass density of $2.75 \mathrm{~g} / \mathrm{cm}^{3}$ and composition of (a-b) $300 \mathrm{ppm} \mathrm{CO}_{2}$, (b) 700 ppm $\mathrm{CO}_{2}$, and $500 \mathrm{CO}_{2}$ - a typical values for Kilauea, Fuego, and Seguam MI respectively (Anderson \& Brown, 1993; Lloyd et al., 2013; Zimmer et al., 2010; see text). This combination of Raman and petrographic analysis predicts that about 2 to $<90$ percent of the total $\mathrm{CO}_{2}$ in these $\mathrm{MI}$ is contained in the bubble (Table 2, 3, 4). These predictions were confirmed by analyses of the MI glass.

concentration assuming $0 \mathrm{ppm}$ in the glass.

The reconstructed $\mathrm{CO}_{2}$ concentration for Kilauea Iki, assuming that the glass contains 0 ppm $\mathrm{CO}_{2}$, ranges from 8 to 4,289 ppm (Table 2, Figure 7a), whereas the $\mathrm{CO}_{2}$ concentration for Kilauea Iki assuming that the glass contains 300 ppm ranges from 308 to 4,589 ppm. Figure 6 shows the proportion of $\mathrm{CO}_{2}$ in the bubble for the Kilauea Iki MI assuming that the glass contains $300 \mathrm{ppm} \mathrm{CO}_{2}$ (for the case where the glass contains $0 \mathrm{ppm} \mathrm{CO}_{2}, 100 \%$ of the $\mathrm{CO}_{2}$ is in the bubble). For example, the line labeled 50\% corresponds to MI for which $50 \%$ of all of the $\mathrm{CO}_{2}$ in the $\mathrm{MI}$ (by mass) is contained in the bubble. The calculated percentage of the total 
amount of $\mathrm{CO}_{2}$ in the $\mathrm{MI}$ that is contained in the bubble ranges from 2 to $93 \%$ for the Iki eruption.

Similarly, the reconstructed $\mathrm{CO}_{2}$ concentration for Kilauea Kapoho ranges from 222 to $5385 \mathrm{ppm}$ (Table 2, Figure 7b), assuming that the glass contains 0 ppm $\mathrm{CO}_{2}$, whereas the $\mathrm{CO}_{2}$ content for Kilauea Kapoho MI ranges from 522 to 5685 ppm assuming that the glass contains $300 \mathrm{ppm} \mathrm{CO}$. Figure $6 \mathrm{~b}$ shows the proportion of $\mathrm{CO}_{2}$ in the bubble for the Kilauea Kapoho MI assuming that the glass contains $300 \mathrm{ppm} \mathrm{CO}_{2}$. The calculated percentage of the total amount of $\mathrm{CO}_{2}$ in the MI that is contained in the bubble ranges from 42 to $97 \%$ for the Kapoho eruption.
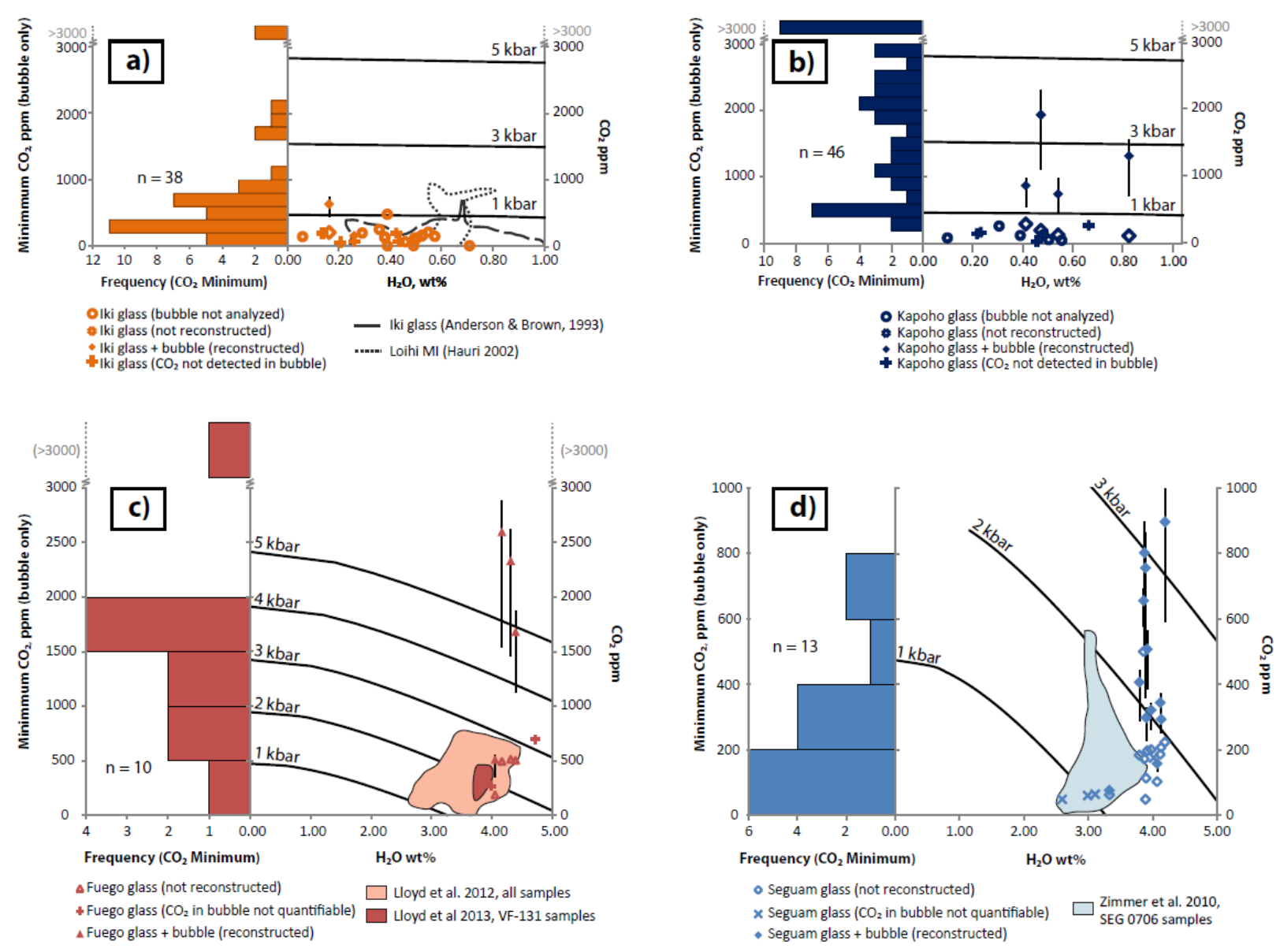


\section{Figure 7}

Figure appears on the previous page. $\mathrm{H}_{2} \mathrm{O}$ and $\mathrm{CO}_{2}$ contents of $\mathrm{MI}$ from a) the $1959 \mathrm{Iki}$ eruption at the summit of Kilauea (Hawaii), b) the 1960 Kapoho eruption on the East Rift Zone of Kilauea, c) the 1974 eruption of Fuego volcano (Guatemala), and d) the 1977 eruption of Seguam Island (Alaska). (a-d) on the left side of each figure is a histogram of minimum concentrations of $\mathrm{CO}_{2}$ in the melt calculated by Raman analysis of MI vapor bubbles only (see text). On the right side of each figure are $\mathrm{H}_{2} \mathrm{O}$ and $\mathrm{CO}_{2}$ concentrations that include both measurements of the glass and vapor portions of the MI. Isobars were calculated with VolatileCalc (Newman \& Lowenstern, 2002). Open symbols indicate volatile contents determined by analyzing the glass. Filled symbols indicate reconstructed melt compositions calculated after Raman analysis of the vapor bubble (see text, Table 6). Crosses indicate volatile contents in the glass in the MI for which $\mathrm{CO}_{2}$ could not be quantified in the bubble. $\mathrm{CO} 2$ in the vapor bubble was quantified using Raman spectroscopy. $a-b)$ Volatile contents in the glass were determined by FTIR (Tuohy et al., in preparation). c-d) Volatile contents in the glass were determined by SIMS at CIW. Dashed and shaded fields delineate MI glass compositions analyzed in other studies of MI from the same four eruptions.

The reconstructed $\mathrm{CO}_{2}$ concentration for Fuego ranges from 293 to 4076 ppm (Table 3, Figure 7c), assuming that the glass contains $0 \mathrm{ppm} \mathrm{CO}_{2}$, whereas the $\mathrm{CO}_{2}$ content for Fuego MI ranges from 993 to $4776 \mathrm{ppm}$ assuming that the glass contains $700 \mathrm{ppm} \mathrm{CO}_{2}$. Figure $6 \mathrm{c}$ shows the proportion of $\mathrm{CO}_{2}$ in the bubble for the Fuego MI assuming that the glass contains $700 \mathrm{ppm}$ $\mathrm{CO}_{2}$. The calculated percentage of the total amount of $\mathrm{CO}_{2}$ in the MI that is contained in the bubble ranges from 30 to $85 \%$ for the Fuego eruption.

The reconstructed $\mathrm{CO}_{2}$ concentration for Seguam ranges from 14 to $707 \mathrm{ppm}$ (Table 4, Figure 7d), assuming that the glass contains $0 \mathrm{ppm} \mathrm{CO}_{2}$, whereas the $\mathrm{CO}_{2}$ content for Seguam MI ranges from 514 to $1207 \mathrm{ppm}$ assuming that the glass contains $500 \mathrm{ppm} \mathrm{CO}$. Figure 6d shows the proportion of $\mathrm{CO}_{2}$ in the bubble for the Seguam MI assuming that the glass contains $500 \mathrm{ppm} \mathrm{CO}_{2}$. The calculated percentage of the total amount of $\mathrm{CO}_{2}$ in the $\mathrm{MI}$ that is contained in the bubble ranges from 3 to $59 \%$ for the Seguam eruption.

\section{The $\mathrm{CO}_{2}$ content of the glass in the $\mathrm{MI}$ is known}

In many cases it is possible to analyze the vapor bubble in the MI by Raman to determine the $\mathrm{CO}_{2}$ density, and then to determine the volatile content of the glass by FTIR or SIMS, as was done here for several MI from each eruption. For the inclusions that we analyzed by both SIMS/FTIR (glass) and Raman (bubble), we reconstructed the $\mathrm{CO}_{2}$ content of the trapped melt using a mass balance approach (Steele-MacInnis et al., 2011) and a correction for PEC (Table 6). 
The reconstructed $\mathrm{CO}_{2}$ contents of MI from Kilauea Iki, Kapoho, Fuego, and Seguam Island are listed in Table 6 and plotted in Figure7a, b, c, and d respectively.

After reconstructing the $\mathrm{CO}_{2}$ contents to include $\mathrm{CO}_{2}$ contained in the bubble, the $\mathrm{CO}_{2}$ concentrations of MI from Fuego range from $513_{-164}^{+46}$ to $2598_{-1054}^{+287} \mathrm{ppm}$, and 63 to $81 \%$ of the total $\mathrm{CO}_{2}$ in the $\mathrm{MI}$ is contained in the bubble (Table 6). Figure 7c shows a summary of the volatile contents of the MI from Fuego: on the left is a histogram depicting minimum $\mathrm{CO}_{2}$ concentrations calculated based on Raman analysis of the bubbles only (see above), and on the right are reconstructed values that include $\mathrm{CO}_{2}$ contents of the glass obtained in this study and similar measurements made by Lloyd et al., (2013). Although we were only able to reconstruct the trapped-melt compositions of four inclusions, these reconstructed values are in agreement with the values estimated by Raman analysis of the bubble only. Figure 7c also shows the measured glass concentrations for $\mathrm{MI}$ with bubbles in which we were unable to quantify the $\mathrm{CO}_{2}$ density (see above). Although we were able to detect $\mathrm{CO}_{2}$ in these $\mathrm{MI}$ by Raman analysis, these bubbles likely contain significantly less $\mathrm{CO}_{2}$ than those in the reconstructed MI. Therefore they could be the result of the contraction of $\mathrm{a} \mathrm{CO}_{2}$-poor melt or slow diffusion of $\mathrm{CO}_{2}$.

After reconstructing the $\mathrm{CO}_{2}$ contents of the MI from Seguam, these MI contain from $77_{-9}^{+1}$ to $896_{-305}^{+102}$ ppm $\mathrm{CO}_{2}$ where $18 \%$ to $93 \%$ of the total $\mathrm{CO}_{2}$ in these MI is in the bubble (Table 6). Figure $7 \mathrm{~d}$ shows a summary of the volatile contents of the MI from Seguam: on the left is a histogram depicting minimum $\mathrm{CO}_{2}$ concentrations calculated based on Raman analysis of the bubbles only (see above), and on the right is a plot of the reconstructed values in relation to our measurements of the $\mathrm{CO}_{2}$ in the glass and similar measurements made by Zimmer et al., (2010). Similar to Fuego, the range in minimum $\mathrm{CO}_{2}$ concentrations is consistent with the range in reconstructed compositions. Figure 7c also shows three MI glass concentrations that represent bubble-bearing MI for which we were unable to quantify the density of $\mathrm{CO}_{2}$ in the bubble by Raman analysis; in two of these $\mathrm{CO}_{2}$ was not detected at all (although there may be some amount of $\mathrm{CO}_{2}$ in these bubbles that is below the detection limits of Raman spectroscopy). These bubbles likely represent MI that trapped a melt that had undergone significant degassing and thus could not diffuse a significant amount of $\mathrm{CO}_{2}$ on the time scale of melt contraction.

Based on FTIR analyses by Tuohy et al. (in preparation), the Kapoho MI contain 37-294 ppm $\mathrm{CO}_{2}$ in the glass. After reconstruction, the melts contain up to $1944_{-825}^{+362} \mathrm{ppm} \mathrm{CO}_{2}$ respectively where 61 to $97 \%$ of the total $\mathrm{CO}_{2}$ contained in the $\mathrm{MI}$ is in the bubble (Table 6). 
Figure $7 \mathrm{~b}$ shows a summary of the volatile contents of the MI from Kapoho: on the left of $7 \mathrm{~b}$ is a histogram depicting minimum $\mathrm{CO}_{2}$ concentrations calculated based on Raman analysis of the bubbles only (see above), and on the right is a plot of the reconstructed values in relation to our measurements of the $\mathrm{CO}_{2}$ in the glass. There were four MI from Kapoho for which we were able to both quantify the amount of $\mathrm{CO}_{2}$ contained in the bubble and measure $\mathrm{CO}_{2}$ in the glass by FTIR (excluding one anomalous inclusion, see below). All four of these MI have reconstructed $\mathrm{CO}_{2}$ concentrations that are significantly higher than those obtained by measuring the glass, and these reconstructed concentrations are also consistent with those obtained by Raman analysis of the bubbles of the smaller MI.

We also note that one of the MI from the Kapoho eruption (Kap 8 Nat R 4w) has a reconstructed $\mathrm{CO}_{2}$ concentration of over $8000 \mathrm{ppm}$ (Table 6). The calculated volume percent $(12.4 \%)$ exceeds our threshold for bubbles that exsolved from the melt after trapping, however the error on our volume percent calculations permits that the bubble could occupy as little as $7.4 \%$ of the inclusion, indicating that the $8000 \mathrm{ppm}$ value could be valid. Gerlach et al. (2002) have shown that the primary magma below Kilauea could contain 7000 ppm $\mathrm{CO}_{2}$ based on observed volatile emission rates above the summit. The MI described above is not plotted on figure $7 \mathrm{~b}$ because it exceeds our volume percent criteria, but we note that that the amount of $\mathrm{CO}_{2}$ contained in this $\mathrm{MI}$ is consistent (within error) with the greatest of the minimum $\mathrm{CO}_{2}$ concentrations (5385 ppm, Kap 8 Nat R 4_12) predicted by Raman analysis of the vapor bubbles only.

Based on FTIR analyses by Tuohy et al. (in preparation), the MI from Kilauea Iki contain 50-471 ppm $\mathrm{CO}_{2}$ in the glass. The reconstructed melts contain up to $624_{-183}^{+116} \mathrm{ppm} \mathrm{CO}_{2}$ where $48 \%$ and $63 \%$ of the total $\mathrm{CO}_{2}$ contained in these $\mathrm{MI}$ is in the bubble (Table 6). Figure 7a shows a summary of the volatile contents of the MI from Kilauea Iki: on the left is a histogram depicting minimum $\mathrm{CO}_{2}$ concentrations calculated based on Raman analysis of the bubbles (see above), and on the right is a plot of the reconstructed values in relation to our measurements of the $\mathrm{CO}_{2}$ in the glass and similar measurements made by Anderson and Brown, (1993). Also shown on Figure 7a are data from MI from Loihi dredge samples (Hauri, 2002), which represent some of the highest concentrations of $\mathrm{CO}_{2}$ measured in situ from MI glasses from Hawaii. The left side of Figure 7a shows that approximately half of the Kilauea Iki MI have minimum $\mathrm{CO}_{2}$ concentrations (from the bubble) that are higher than the concentrations of $\mathrm{CO}_{2}$ measured in the 
glass. However, out of the $75 \mathrm{MI}$ that we analyzed, of which about $60 \%$ contain bubbles with quantifiable $\mathrm{CO}_{2}$, only two of these vapor bubble-bearing MI could be analyzed by FTIR so that the proportions of $\mathrm{CO}_{2}$ in the bubble and in the glass could be directly compared. The requirement that MI be polished on two sides for FTIR analysis restricts sampling of MI to only the largest samples, and the larger Kilauea Iki MI were typically crosscut by fractures in the host olivine. Although the two reconstructed $\mathrm{CO}_{2}$ compositions do not represent the full range of minimum $\mathrm{CO}_{2}$ contents that we observed, they correspond with a majority of the minimum $\mathrm{CO}_{2}$ concentrations.

Having analyzed the $\mathrm{CO}_{2}$ content of the glass in several of our MI, it is possible to compare the percent $\mathrm{CO}_{2}$ contained in the bubble with the predicted percent of $\mathrm{CO}_{2}$ in the bubble calculated above using analyses of similar MI. This comparison is shown in Figure 8. For almost every MI in all four eruptions, our predicted value was lower than the value calculated from measurements of both the glass and the bubble - typically by about $20 \%$. This is because we used an upper value from the range of measured glass compositions reported by previous authors for each eruption. This was done because the $\mathrm{CO}_{2}$ concentration in the glass has a log-normal distribution in some cases (Figure 8b, d), and we wanted to avoid overestimating the percent of total $\mathrm{CO}_{2}$ contained in the bubble. If we had taken a less conservative approach and used an average value instead, the predicted values would be higher. 


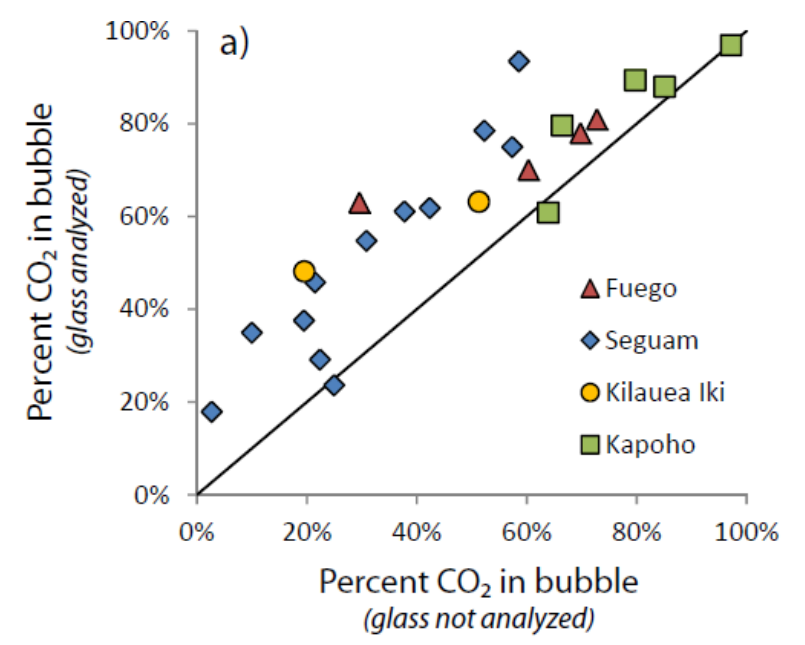

Fuego

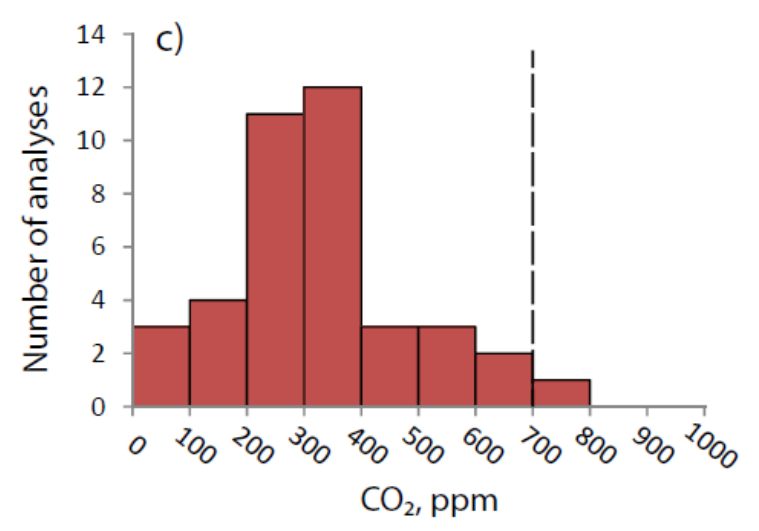

b)

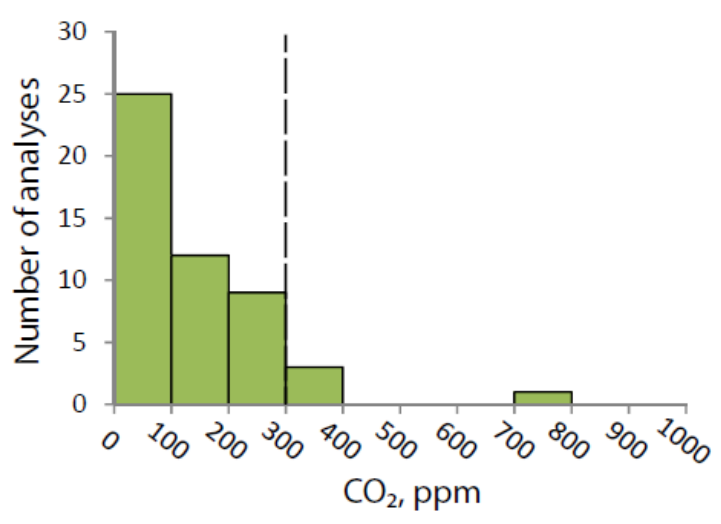

Seguam

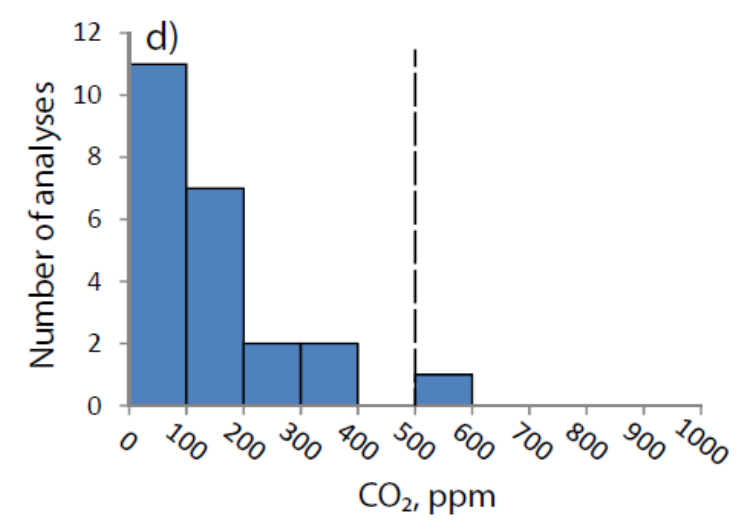

\section{Figure 8}

A comparison of predicted and measured percent of total $\mathrm{CO}_{2}$ contained in the bubble based on analyses of similar MI. a) Percent of $\mathrm{CO}_{2}$ contained in the bubble based on SIMS and FTIR analyses of the glass and Raman analyses of the glass plotted against values calculated using Raman analyses only and upper estimates of $\mathrm{CO}_{2}$ from the literature. $b$-d) the distribution of $\mathrm{CO}_{2}$ concentrations measured from Kilauea, Fuego, and Seguam MI by Anderson and Brown (1993), Lloyd et al. (2013), and Zimmer et al., (2010) respectively. The dashed lines indicate the values used to predict the percentage of $\mathrm{CO}_{2}$ contained in the bubble for the MI that have not been analyzed by FTIR or SIMS. 


\section{DISCUSSION}

\section{Reconstructing the $\mathrm{H}_{2} \mathrm{O}$ content of the $\mathrm{MI}$}

In addition to $\mathrm{CO}_{2}$, it is also likely that $\mathrm{H}_{2} \mathrm{O}$ has exsolved into the vapor phase (the bubble). However, $\mathrm{H}_{2} \mathrm{O}$ is significantly more soluble than $\mathrm{CO}_{2}$ for the melt compositions $\left(\mathrm{SiO}_{2}\right.$ $\mathrm{wt} \% \approx 49$ ) considered in this study, and it is unlikely that the change in the composition of the glass due to diffusion of $\mathrm{H}_{2} \mathrm{O}$ from the melt into the bubble is significant. Determining the amount of $\mathrm{H}_{2} \mathrm{O}$ in the vapor phase using Raman spectroscopy alone is difficult because, unlike $\mathrm{CO}_{2}, \mathrm{H}_{2} \mathrm{O}$ appears in the Raman spectrum of both the glass and vapor phases (i.e. we are not yet able to distinguish the source of the $3500 \mathrm{~cm}^{-1} \mathrm{O}-\mathrm{H}$ band when analyzing a bubble that is surrounded in glass that also contains $\mathrm{H}_{2} \mathrm{O}$ ). For this reason, we used a solubility model (e.g. Dixon et al., 1995; Newman \& Lowenstern, 2002; Papale et al., 2006) combined with the $\mathrm{CO}_{2}$ density in the vapor obtained by Raman analysis of the bubble to calculate the total mass of $\mathrm{H}_{2} \mathrm{O}$ in the bubble. We calculated the mole fraction of $\mathrm{H}_{2} \mathrm{O}$ in the vapor that is in equilibrium with the melt (glass) using the model of Dixon et al. (1995). We then calculated the density of $\mathrm{H}_{2} \mathrm{O}$ in the vapor using the weight fraction of $\mathrm{H}_{2} \mathrm{O}$ in the vapor and the density of $\mathrm{CO}_{2}$ in the vapor phase determined by Raman spectroscopy. Using the same mass balance approach that was used to reconstruct $\mathrm{CO}_{2}$ concentrations in the trapped melt (Steele-MacInnis et al., 2011), we added the $\mathrm{H}_{2} \mathrm{O}$ in the bubble back into the melt (glass) and calculated the percent of total $\mathrm{H}_{2} \mathrm{O}$ that is contained in the bubble (Table 6). For almost all of our samples, $<1 \%$ to $5 \%$ of the total $\mathrm{H}_{2} \mathrm{O}$ is contained in the bubble with an outlier (Seg 15.1) that contains $10 \%$ of the $\mathrm{H}_{2} \mathrm{O}$. In most cases the change in $\mathrm{wt} \% \mathrm{H}_{2} \mathrm{O}$ is about $0.05 \mathrm{wt} \%$. This amount is comparable to the error associated with analyzing the $\mathrm{H}_{2} \mathrm{O}$ content by SIMS (0.01-0.05 wt\%) and FTIR ( $\left.>0.5 \mathrm{wt} \%\right)$, Therefore we conclude that the $\mathrm{H}_{2} \mathrm{O}$ that may be contained in the bubble is negligible for the $\mathrm{MI}$ in this study.

\section{Reconstruction of MI volatile budgets using PVTX data for melt-volatile systems}

In this study, we determined the amount of $\mathrm{CO}_{2}$ contained in the bubbles of bubblebearing MI based on in situ Raman analysis. However, it is also possible to estimate the composition and density of vapor bubbles in MI using information on the solubility of volatiles in the melt combined with an equation of state (EOS) for the fluid. With this method, the volatile content of the glass obtained by SIMS or FTIR analysis is used to estimate the pressure in the MI at the moment that the volatile content of the melt was "locked in" during cooling - this is 
generally assumed to occur at the glass transition temperature. Then, using a volatile solubility model such as VolatilCalc (Newman \& Lowenstern, 2002) or the model of Papale et al. (2006), the composition of the vapor phase that is in equilibrium with the melt at the calculated pressure and the glass transition temperature is determined. Finally, the density of the vapor phase is estimated using either the IGL or some other EOS.

As an example of the application of this method, Shaw et al. (2008) calculated the volatile content of MI from the Mariana Arc and estimated that $\sim 80 \%$ of the $\mathrm{CO}_{2}$ (and about $2 \%$ of the $\mathrm{H}_{2} \mathrm{O}$ ) in the MI was contained in the bubble. These workers used the IGL ( $\mathrm{n}=\mathrm{PV} / \mathrm{RT}$ ) to estimate the fluid density. Here, we have reconstructed the $\mathrm{CO}_{2}$ contents for our MI using the IGL as well as a commonly-used EOS. Pressures in the MI were estimated using VolatileCalc (Newman \& Lowenstern, 2002), and vapor bubble volumes were calculated from the measured bubble diameters. We assumed glass transition temperatures of $700{ }^{\circ} \mathrm{C}$ for Fuego and Seguam MI and $825^{\circ} \mathrm{C}$ for Kilauea Iki and Kapoho MI (Bouhifd et al., 2006). The amount (mass) of $\mathrm{CO}_{2}$ in the bubble was calculated using the IGL and the mole fraction of $\mathrm{CO}_{2}$ in the vapor predicted by the Newman and Lowenstern (2002) solubility model. The reconstructed $\mathrm{CO}_{2}$ concentrations were calculated using the same mass balance approach described above, and the results are shown in Figure 9a.

For comparison, we also reconstructed the MI compositions using the EOS of Mao et al. (2009, hereafter the "Mao EOS") that was developed to predict PVT properties of mixed $\mathrm{H}_{2} \mathrm{O}$ $\mathrm{CO}_{2}$ fluids. The reconstruction used the same glass transition temperatures, pressures, and vapor compositions as described above. The calculated density was then used to determine the amount of $\mathrm{CO}_{2}$ and $\mathrm{H}_{2} \mathrm{O}$ in the bubble, again using the vapor composition predicted by VolatileCalc. Figure $9 \mathrm{~b}$ shows reconstructed $\mathrm{CO}_{2}$ concentrations estimated using the Mao EOS compared to those calculated using the IGL. At the PTX conditions used, both methods predict similar results, although the reconstructed $\mathrm{CO}_{2}$ concentrations calculated using the Mao EOS are slightly higher than those calculated using the IGL for concentrations below $2000 \mathrm{ppm}$, and significantly less for concentrations above $2000 \mathrm{ppm}$.

Our comparison suggests that reconstructing the $\mathrm{CO}_{2}$ content of a MI using the IGL or some other EOS overestimates the $\mathrm{CO}_{2}$ concentrations in the melt by up to a factor of 6 , compared to values estimated based on Raman analysis (Figure 9a). We suggest that this 

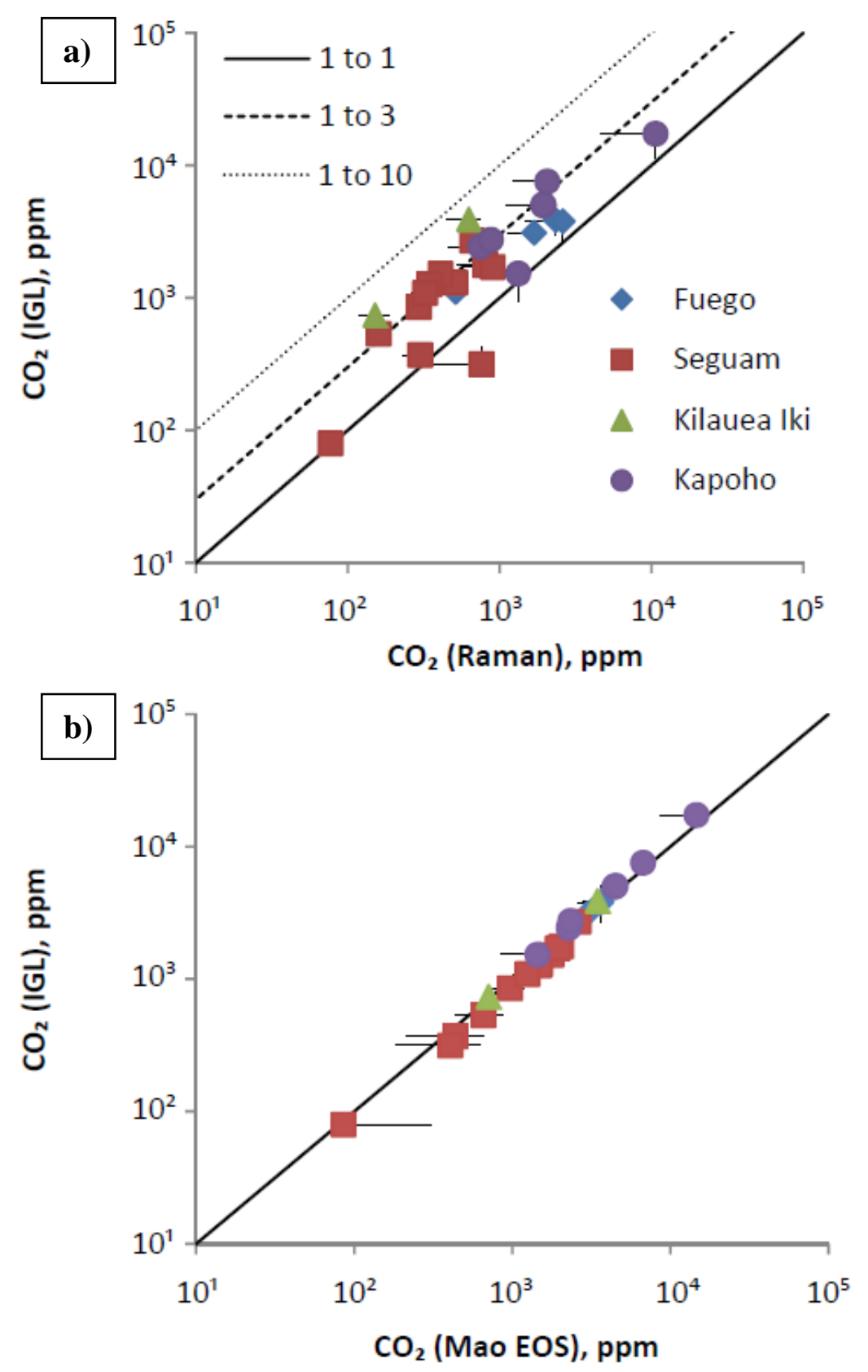

\section{Figure 9}

Reconstructed $\mathrm{CO}_{2}$ concentrations calculated using the Ideal Gas Law (IGL), an empiricallyderived equation of state (Mao EOS), and in situ Raman analysis of the bubble are compared. a) reconstructed $\mathrm{CO}_{2}$ concentrations calculated with the IGL and Raman analysis. A 1 to 1 reference line is plotted as a solid line, and the dashed lines represent 1 to 3 and 1 to 10 reference lines that delineate points where the IGL overestimates the $\mathrm{MI} \mathrm{CO}_{2}$ contents by a factor of 3 and a factor of 10 respectively. b) reconstructed $\mathrm{CO}_{2}$ contents calculated with the IGL and the Mao EOS. Both equations of state produce similar results for the P-T conditions that affected the MI in this study (see text). 
difference reflects the fact that the Raman technique is measuring the actual amount of $\mathrm{CO}_{2}$ that is contained in the vapor bubble, whereas the IGL method assumes that the bubble size and the amount of volatile it contains represents equilibrium between the melt and the vapor. As noted by Anderson and Brown (1993) and Riker (2005), a limitation of using the IGL to estimate the density of vapor phase is that the vapor bubble is likely to expand during quenching on a timescale too fast for volatiles to diffuse from the melt and into the bubble to maintain equilibrium between the volatile content of the melt and the volatiles in the bubble. Recently, detailed mapping of the volatile distribution in MI and the surrounding host phase has provided additional evidence to support the heterogeneous distribution of volatiles in some MI (Esposito et al., 2014). As a result, while the final size of the bubble represents its equilibrium pre-eruptive size, the amount of $\mathrm{CO}_{2}$ contained in the bubble is less than would be predicted assuming equilibrium between the melt and the vapor. In summary, if one has data for the volatile content of the glass from FTIR or SIMS analysis and then uses the IGL or some other EOS to reconstruct the bulk volatile content of the melt, it is likely that the predicted volatile content would be higher than the true concentration, perhaps by about one-half of an order of magnitude.

Conversely, if data are not available for the volatile content of the glass, one could assume a volatile concentration, perhaps based on previous studies or comparison with similar geologic environments, and then use the IGL to obtain a "ballpark" estimate of the volatile content of the melt. However, such estimates would have a large but unconstrained uncertainty, and should not be used to infer depths of formation or magma degassing paths.

\section{Carbonate Phases in Melt Inclusions}

As noted above, carbonates were observed in the bubbles in MI from Seguam, Fuego, and in a few MI from Kapoho. The occurrence of carbonates (and other minerals) on the bubble wall has been observed in MI from various volcanic settings (Kamenetsky and Kamenetsky, 2010 and references therein). However, such phases are usually not reported in studies that focus on volcanic degassing behavior (e.g., Kamenetsky et al., 2007). The presence of carbonate minerals on the bubble wall implies that analysis of the glass phase and vapor bubbles in MI may not completely account for all of the $\mathrm{C}$ that was originally trapped in a $\mathrm{MI}$ as dissolved $\mathrm{CO}_{2}$. Moreover, it is not clear if this reaction (Andersen et al., 1984) could be reversed on a time scale fast enough to avoid $\mathrm{H}^{+}$diffusion from the inclusion. 
The presence of carbonates in the MI from Fuego and Seguam also raises questions concerning the relative rarity of $\mathrm{CO}_{2}$ in the vapor phase of these MI.. While $\mathrm{CO}_{2}$ was detected in the bubbles of a smaller proportion of the MI from Fuego and Seguam as compared to the samples from Kapoho, carbonate minerals were detected in a greater proportion of MI from Fuego and Seguam, compared to those from the two Kilauea eruptions. In all four analyses where carbonate was detected during analyses of vapor bubbles from Kapoho, $\mathrm{CO}_{2}$ was also detected (Table 2). However, $\mathrm{CO}_{2}$ was detected in the vapor bubbles in only two of the sixteen MI from Fuego volcano in which carbonate was also detected (Table 3); similarly, $\mathrm{CO}_{2}$ was detected in the vapor bubble in only two of the nine MI from Seguam in which carbonates were detected by Raman analysis or by visual inspection (Table 4, Figure 3e,f). Because of these discrepancies, it is likely that a significant portion of the $\mathrm{CO}_{2}$ that exsolved from the melt after the Fuego and Seguam MI were trapped is sequestered in carbonate phases. It is beyond the scope of the present study to quantify the contribution of these carbonates to the $\mathrm{CO}_{2}$ budget of these MI. We can only conclude that the total amounts of $\mathrm{C}$ reported for the MI that contained carbonate ( 2 of $23 \mathrm{MI}$, Table 6) are underestimates in that they do not include the $\mathrm{C}$ contained in the carbonate solids.

\section{Revised depths and pressures of formation}

The trapping pressures and depths for the inclusions from Kilauea, Fuego and Seguam have been revised based on our new volatile data, using two mixed solubility models. The isobars shown in Figure 7 were calculated using VolatileCalc (Newman and Lowenstern, 2002), and the individual trapping pressures listed in Table 6 were calculated using the model of Dixon et al. (1995) to account for the $\mathrm{SiO}_{2}$ content of each inclusion. Table 6 shows a comparison of the trapping pressures and depths (assuming $3.5 \mathrm{~km} / \mathrm{kbar}$ ) before and after reconstructing the $\mathrm{CO}_{2}$ contents for the Kilauea, Fuego, and Seguam samples. The revised trapping pressures for Fuego and Seguam MI are discussed below; the MI from Kilauea are discussed by Tuohy et al. (in preparation).

Using the reconstructed $\mathrm{CO}_{2}$ concentrations for Fuego MI, the calculated trapping pressures span a range from 2.6 to $6.0 \mathrm{kbars}$, which corresponds to depths of 9 to $22 \mathrm{~km}$. For comparison, the volatile content of the glass yields a range in trapping pressures of 1.9 to 2.5 kbar, which corresponds to depths of 7 to $10 \mathrm{~km}$. Lloyd et al. (2013) report trapping depths of 7 $8 \mathrm{~km}$, and Rose et al (1978) suggest that crystallization could have begun between 5 and $10 \mathrm{~km}$; 
both estimates are based on melt-volatile solubility. Using an alternate method, Roggensack (2001) predicted a range from $<3-13 \mathrm{~km}$ for trapping depths based on a crystal size indicator. The calculated trapping pressures for the Seguam MI based on the reconstructed $\mathrm{CO}_{2}$ concentrations are up to $3.4 \mathrm{kbar}$, corresponding to a depth of $\sim 12 \mathrm{~km}$. For comparison, the trapping pressures calculated using volatile concentrations measured from the glass only are 0.9 to $2.5 \mathrm{kbars}$, corresponding to depths of $3-9 \mathrm{~km}$. The revised pressures and depths are consistent with Jicha et al. (2006) who predicted 3-5 kbar ( 10-15 km) as the depth where basalt parent magmas began to crystallize based on isotopic data and modal mineralogy.

\section{Concluding Remarks}

In this study, in order to obtain a complete volatile budget, we have measured both the amount of $\mathrm{CO}_{2}$ contained in the bubble and the amount of $\mathrm{CO}_{2}$ contained in the glass for a suite of bubble-bearing melt inclusions (MI). We have determined that in many cases, most of the $\mathrm{CO}_{2}$ in a bubble-bearing MI is contained in the bubble. Based on our analysis of over 230 bubblebearing MI, we agree with the conclusions of other studies (Anderson and Brown, 1993;

Cervantes et al., 2002; Shaw et al., 2008; Esposito et al., 2011; Bucholz et al., 2013; Hartley et al., 2014), that $\mathrm{CO}_{2}$-bearing vapor bubbles are common in $\mathrm{MI}$ from volcanic systems. Estimates of the total volatile budget of the MI that do not include the $\mathrm{CO}_{2}$ contained in the bubble either by reheating or in situ Raman analysis, will either significantly underestimate the total amount of $\mathrm{CO}_{2}$ in the MI, or report a false degassing trend in $\mathrm{MI}$ that is similar to that resulting from open system degassing. Using the mass balance approach described by Steele-MacInnis et al. (2011) that we have applied in this study, the complete volatile budget of the MI can be determined if the amount of $\mathrm{CO}_{2}$ contained in the bubble is measured and added back into the melt. 


\section{REFERENCES}

Andersen, T., O'Reilly, S. Y., Griffin, W. L. (1984) The trapped fluid phase in upper mantle xenoliths from Victoria, Australia: implications for mantle metasomatism. Contributions to Mineralogy and Petrology, 88, 72-85.

Anderson, A. T., Davis, A. M., Lu, F. (2000) Evolution of Bishop Tuff rhyolitic magma based on melt and magnetite inclusions and zoned phenocrysts. Journal ofPetrology, 41 (3), 4449473.

Anderson, A. T., Brown, G. G. (1993) CO2 contents and formation pressures of some Kilauean melt inclusions. American Mineralogist, 78, 794-803.

Bodnar, R. J., Student, J. J. (2006) Melt inclusions in plutonic rocks: Petrography and microthermometry. Melt Inclusions in Plutonic Rocks (J. D. Webster, ed.), Mineral Assoc. Canada, Short Course 36, 1-26.

Bouhifd, M. A., Besson, P., Courtial, P., Ge'rardin, C., Navrotsky, A., Richet, P. (2007) "Thermochemistry and melting properties of basalt." Contrib Mineral Petrol, 153, 689698.

Borisov, A. A. \& Shapkin, A. I. (1990). A new empirical equation rating Fe3+/Fe2+ in magmas to their composition, oxygen fugacity, and temperature. Geochemistry International, 27, 111-116.

Bucholz, C. E., Gaetani, G. A., Behn, M. D., Shimizu, N., (2013) Post-entrapment modification of volatiles and oxygen fugacity in olivine-hosted melt inclusions. Earth \& Planetary Science Letters, 374, 145-155.

Burke, E. A. J. (1994) Raman microspectrometry of fluid inclusions. In: De Vivo, B., Frezzotti, M.L. (Eds.), Fluid Inclusions in Minerals: Method and Applications. Short Course of Working Group (IMA) "Inclusions in Minerals", Virginia Polytechnic Institute and State University, pp. 25-44.

Burnham, W.C. and Ohmoto, H. 1980. Late-stage processes of felsic magmatism. Society of Mining Geologists of Japan, Special Volume 8, 1-11.

Burruss, R.C. (2003) Raman spectroscopy of fluid inclusions. In: Samson, I., Anderson, A., Marshall, D. (Eds.), Fluid inclusions: analysis and interpretation, Mineralogical Association of Canada, short course series, 32, pp. 279-289.

Cervantes, P., Kamenetsky, V. \& Wallace, P. (2002). Melt inclusion volatile contents, pressures of crystallization for Hawaiian picrites, and the problem of shrinkage bubbles. EOS, Transactions, American Geophysical Union 83, F1495-F1496. 
Cervantes, P., Wallace, P. (2003) Magma degassing and basaltic eruption styles: a case study of 2000 year BP Xitle volcano in central Mexico. Journal of Volcanology and Geothermal Research, 120, 249-270.

Danyushevsky L. V., McNeill, A. W., Sobolev, A. V. (2002) Experimental and petrological studies of melt inclusions in phenocrysts from mantle-derived magmas: an overview of techniques, advantages and complications. Chemical Geology, 183, 5-24.

Danyushevsky, L. V., Plechov, P. (2011) Petrolog3: Integrated software for modeling crystallization processes." Geochemistry, Geophysics, Geosystems, 12, 7, 32 p.

Dixon, J. E., Stolper, E. M., Holloway, J. R. (1995) An experimental study of water and carbon dioxide solubilities in mid-ocean ridge basaltic liquids. Part I: Calibration and solubility models. Journal of Petrology, 36 (6), 1607-1631.

Esposito, R., Bodnar, R. J., Danyushevsky, L. V., de Vivo, B., Fedele, L., Hunter, J., Lima, A., Shimizu, N. (2011) Volatile evolution of magma associated with the Solchiaro eruption in the Phlegrean Volcanic District (Italy). Journal of Petrology, 52 (12), 2431-2460.

Esposito, R., Hunter, J., Schiffbauer J.D., Shimizu N., Bodnar, R. J. (2014) An assessment of the reliability of melt inclusions as recorders of the pre-eruptive volatile content of magmas. Am. Mineral., in press.

Fall, A., Tattitch, B., Bodnar, R. J. (2011) Combined microthermometric and Raman spectroscopic technique to determine the salinity of $\mathrm{H} 2 \mathrm{O}-\mathrm{CO} 2-\mathrm{NaCl}$ fluid inclusions based on clathrate melting. Geochimica et Cosmochimica, 75, 951-964.

Ford, C. E., Russell, D. G., Craven, J. A., Fisk, M. R. (1983). Olivine-liquid equilibria; temperature, pressure and composition dependence of the crystal/liquid cation partition coefficients for $\mathrm{Mg}, \mathrm{Fe} 2+, \mathrm{Ca}$ and Mn. Journal of Petrology 24, 256-265.

Frezzotti, M. L., Tecce, F., Casagli, A. (2012) Raman spectroscopy for fluid inclusion analysis. Journal of Geochemical Exploration, 112, 1-20.

Gaetani, G., O’Leary, J., Shimizu, N. (2012) Post-entrapment changes to H2O and CO2 in olivine-hosted melt inclusions. Mineralogical Magazine, 75, 879.

Gazel, E., Plank, T., Forsyth, D. W., Bendersky, C., Lee, C-T. A., Hauri, E. H. (2012) Lithosphere versus asthenosphere mantle sources at the Big Pine Volcanic Field, California. Geochemistry, Geophysics, Geosystems, 13, 1-25.

Gerlach, T. M., McGee, K. A., Elias, T., Sutton, A. J., Doukas, M. P. (2002) Carbon dioxide emission rate of Kilauea Volcano: Implications for primary magma and the summit reservoir. Journal of Geophysical research, vol. 107, no. B9, 2189

Hartley, M. E., Maclennan, J., Edmonds, M., Thordarson, T. (2014) Reconstructing the deep $\mathrm{CO} 2$ degassing behavior of large basaltic fissure eruptions. Earth and Planetary Science Letters, 393, 120-121. 
Hauri, E. (2002) SIMS analysis of volatiles in silicate glasses, 2: isotopes and abundances in Hawaiian melt inclusions. Chemical Geology, 183, 115-141.

Hauri, E. H., Kent, A. J. R., Arndt, N. (2002) Melt inclusions at the millennium: Toward a deeper understanding of magmatic processes., Chem. Geol. 103, 378 p.

Helo, C., M-A., Longpré, Shimizu, N., Clague, D. A., Stix, J. (2011) Explosive eruptions at midocean ridges driven by CO2-rich magmas. Nature Geoscience, 4, 260-263.

Jicha, B. R., Singer, B. S., (2006) "Volcanic history and magmatic evolution of Seguam Island, Aleutian Island arc, Alaska." GSA Bulletin, 118, 7/8, 805-822.

Johnson, E. R., Wallace, P. J., Cashman, K. V., Granados, H. D., Kent, A. J. R. (2008) Magmatic volatile contents and degassing-induced crystallization at Volcán Jorullo, Mexico: Implications for melt evolution and the plumbing systems of monogenetic volcanoes. Earth and Planetary Science Letters, 269, 478-487.

Kamenetsky, V. S., Davidson, P., Mernagh, T. P., Crawford, A. J., Gemmell, J. B., Portnyagin, M. V., Shinjo, R. (2002) Fluid bubbles in melt inclusions and pillow-rim glasses: hightemperature precursors to hydrothermal fluids? Chemical Geology, 183, 349-364.

Kamenetsky, V. S., Kamenetsky, M. B. (2010) "Magmatic fluids immiscible with silicate melts: examples from inclusions in phenocrysts and glasses, and implications for magma evolution and metal transport."Geofluids, 10, 293-311.

Kamenetsky, V. S., Pompilio, M., Metrich, N., Sobolev, A. V., Kuzmin, D. V., Thomas, R. (2007) Arrival of extremely volatile-rich high-Mg magmas changes explosivity of Mount Etna. Geology, 35 (3), 255-258.

Kawakami, Y., Yamamoto, J., Kagi, H. (2003) Micro-Raman densimeter for CO2 inclusions in mantle-derived minerals. Applied Spectroscopy, 57, 1334-1339.

Lange, R. A. \& Carmichael, I. S. E. (1987). Densities of Na2O-K2O-MgO-MgO-FeO-Fe2O3A13O3-TiO2-SiO2 liquids: New measurements and derived partial molar properties. Geochimica et Cosmochimica Acta 51, 2931-2946.

Liu, Y., Anderson, A. T., Wilson, C. J. N., Davis, A. M., Steele, I. M. (2006) Mixing and differentiation in the Oruanui rhyolitic magma, Taupo, New Zealand: Evidence from volatiles and trace elements in melt inclusions. Contributions to Mineralogy and Petrology, 151, 71-87.

Lloyd, A. S., Plank, T., Ruprecht, P., Hauri, E. H., Rose, W. (2013) Volatile loss from melt inclusions in pyroclasts of differing sizes. Contrib Mineral Petrol, (published online) online 28 September 2012.

Lowenstern, J. B. (1994) Dissolved volatile concentrations in an ore-forming magma. Geology, 22, 893-896. 
Lowenstern, J. B. (1995) Applications of silicate-melt inclusions to the study of magmatic volatiles. In: Thompson, J. F. H. (ed.) Magmas, fluids and ore deposition: Mineralogical Association of Canada, Short Course 23, 71-99.

Lowenstern, J. B. (2003) Melt inclusions come of age: Volatiles, volcanoes, and Sorby's legacy. in Melt inclusions in Volcanic Systems, De Vivo B \& Bodnar RJ, Eds., Elsevier Amsterdam, 1-21.

Mangiacapra, A., Moretti, R., Rutherford, M., Civetta, L., Orsi, G., Papale, P. (2008) The deep magmatic system of the Campi Flegrei caldera (Italy). Geophysical Research Letters, 35, $1-6$.

Mao, S., Duan, Z., and Hu, W. (2009) A vapor-liquid phase equilibrium model for binary CO2$\mathrm{H} 2 \mathrm{O}$ and $\mathrm{CH} 4-\mathrm{H} 2 \mathrm{O}$ systems above 523 degree $\mathrm{C}$ for application to fluid inclusions. The Journal of Supercritical Fluids 50, 13-21.

Massare, D., Metrich, N., Clocchiatti, R. (2002) High-temperature experiments on silicate melt inclusions in olivine at $1 \mathrm{~atm}$ : inference on temperatures of homogenization and $\mathrm{H} 2 \mathrm{O}$ concentrations. Chemical Geology, 183, 87-98.

Metrich, N., Wallace, P. J. (2008) Volatile abundances in basaltic magmas and their degassing paths tracked by melt inclusions. Reviews in Mineralogy \& Geochemistry, 69, 363-402.

Newman, S., Lowenstern, J. B. (2002) VolatileCalc: a silicate melt-H2O-CO2 solution model written in Visual Basic for excel. Computers \& Geosciences, 28, 597-604.

Papale, P., Moretti, R., Barbato, D. (2006) The compositional dependence of the saturation surface of $\mathrm{H} 2 \mathrm{O}+\mathrm{CO} 2$ fluids in silicate melts. Chemical Geology, 229, 78-95.

Richter, D.H., Eaton, J.P., Murata, K.J., Ault, W.U., and Krivoy, H.L. (1970) Chronological narrative of the 1959-60 eruption of Kilauea Volcano, Hawaii. U.S. Geological Survey Professional Paper 537-E, 73 p.

Riker, J. M. (2005) “The 1859 Eruption of Mauna Loa Volacano, Hawai'i: Controls on the Development of Long Lava Channels." unpublished thesis, 175 p.

Roedder, E. (1979) Origin and significance of magmatic inclusions. Bulletin de Mineralogie, $102,467-510$.

Roedder, E. (1984) Fluid Inclusions. Mineralogical Society of America, Reviews in Mineralogy, v. 12,644 p.

Roggensack, K. (2001) "Unraveling the 1974 eruption of Fuego volcano (Guatemala) with small crystals and their young melt inclusions." Geology, 29, 10, 911-914.

Roggensack, K., Hervig, R. L., McKnight, S. B., Williams, S. N. (1997) “Explosive Basaltic Volcanism from Cerro Negro Volcano: Influence of Volatiles on Eruptive Style." Science, 227, 5332, 1639-1642. 
Rose, W. I., Anderson, A. T., Woodruff, L. G., Bonis, S. B. (1978) The October 1974 basaltic tephra from Fuego Volcano: Description and history of the magma body. Journal of Volcanology and Geothermal Research, 4, 3-53.

Ruscitto, D. M., Wallace, P. J., Johnson, E. R., Kent, A. J. R., Bindeman, I. N. (2010) Volatile contents of mafic magmas from cinder cones in the Central Oregon High Cascades: Implications for magma formation and mantle conditions in a hot arc. Earth and Planetary Science Letters, 298, 153-161.

Schipper, C. I., White, J. D. L., Houghton, B. F., Shimizu, N., Stewart, R. B. (2010) Explosive submarine eruptions driven by volatile-coupled degassing at Loihi Seamount, Hawaii. Earth and Planetary Science Letters, 295, 497-510.

Severs, M. J., Azbej, T., Thomas, J. B., Mandeville, C. W., Bodnar, R. J. (2007) Experimental determination of $\mathrm{H} 2 \mathrm{O}$ loss from melt inclusions during laboratory heating: Evidence from Raman spectroscopy. Chemical Geology, 237, 358-371.

Shaw, A. M., Hauri, E. H., Fischer, T. P., Hilton, D. R., Kelly, K. A. (2008) Hydrogen isotopes in Mariana arc melt inclusions: Implications for subduction dehydration and the deepEarth water cycle. Earth and Planetary Science Letters, 275, 138-145.

Sparks, R. S. J. (1978) The dynamics of bubble formation and growth in magmas: a review and analysis. Journal of Volcanology and Geothermal Research, (3) 1-37.

Spilliaert, N., Allard, P., Metrich, N., Sobolev, A. V. (2006) Melt inclusion record of the conditions of ascent, degassing, and extrusion of volatile-rich alkali basalt during the powerful 2002 flank eruption of Mount Etna (Italy). Journal of Geophysical Research, $111,19 \mathrm{p}$.

Steele-MacInnis, M., Esposito, R., Bodnar, R. J., (2011) Thermodynamic model for the effect of post-entrapment crystallization on the $\mathrm{H} 2 \mathrm{O}-\mathrm{CO} 2$ systematics of vapor-saturated, silicate melt inclusions. Journal of Petrology, 52, 2461-2482.

Sterner, S. M., Bodnar, R. J. (1984) Synthetic fluid inclusions in natural quartz I. Compositional types synthesized and applications to experimental geochemistry. Geochimica et Cosmochimica Acta, 48, 2659-2668.

Stolper, E., Holloway, J. R. (1988) Experimental determination of the solubility of carbon dioxide in molten basalt at low pressure. Earth and Planetary Science Letters, 87, 397408.

Thomas, J. B., Bodnar, R. J. (2002) A technique for mounting and polishing melt inclusions in small $(<1 \mathrm{~mm})$ crystals. American Mineralogist, 87, 1505-1508.

Tilling, R. I., Dvorak, J. J. (1993) “Anatomy of a basaltic volcano.” Nature, 363, 125-133.

Vigouroux, N., Wallace, P. J., Kent, A. J. R. (2008) Volatiles in high-K magmas from the western Trans-Mexican Volcanic Belt: Evidence for fluid fluxing and extreme 
enrichment of the mantle wedge by subduction processes. Journal of Petrology, 49 (9), $1589-1618$.

Walker, J. A. (2003) The water and trace element contents of melt inclusions across an active subduction zone. Contrib. Mineral. Petrol., 146, 62-77.

Wallace, P.J. (2005) Volatiles in subduction zone magmas: concentrations and fluxes based on melt inclusion and volcanic gas data. Journal of Volcanology and Geothermal Research, $140,217-240$.

Wallace, P. J., Anderson, A. T., Davis, A. M. (1999) Gradients in H2O, CO2, and exsolved gas in a large-volume silicic magma system: Interpreting the record preserved in melt inclusions from the Bishop Tuff. Journal of Geophysical Research, 104, B9, 20,097 20,122 .

Wallace, P. J., Gerlach, T. M. (1994) Magmatic Vapor Source for Sulfur Dioxide Released During Volcanic Eruptions: Evidence from Mount Pinatubo. Science, 265, 497-499.

Wallace, P. J., Kamenetsky, V. S., Cervantes, P. (2014) Melt Inclusion CO2 Contents, Pressures of Olivine Crystallization, and the Problem of Shrinkage Bubbles. Am. Mineral., in review.

Webster, J. D., Raia, F., De Vivo, B., Rolandi, G. (2001) The behavior of chlorine and sulfur during differentiation of the Mt. Somma-Vesuvius magmatic system. Mineralogy \& Petrology, 73, 177-200.

Zimmer, M. M., Plank, T., Hauri, E. H., Yogodzinski, G. M., Stelling, P., Larsen, J., Singer, B., Jicha, B., Mandeville, C., Nye, C. J. (2010) The role of water in generating the calcalkaline trend: New volatile data for Aleutian magmas and a new tholeiitic index. Journal of Petrology, 51(12), 2411-2444. 


\section{APPENDIX}

Tables

Table 1: Sources of MI data

\begin{tabular}{|c|c|c|c|c|}
\hline Value & Kilauea Iki & Kapoho & Fuego & Seguam \\
\hline $\mathrm{CO}_{2}$ density in bubble ${ }^{\mathrm{a}}$ & Raman & Raman & Raman & Raman \\
\hline Volatile concentrations in glass ${ }^{b}$ & FTIR & FTIR & SIMS & SIMS \\
\hline Major elements ${ }^{c}$ & EPMA & EPMA & EPMA & EPMA \\
\hline PEC correction ${ }^{d}$ & Tuohy et al. & Tuohy et al. & petrolog3 & petrolog3 \\
\hline
\end{tabular}

${ }^{\mathrm{a}}$ Density of $\mathrm{CO}_{2}$ in the bubble was determined for all eruptions by Raman analysis at Virginia Tech (VT). Samples for which we have analyzed vapor bubbles only and not the composition of the glass are indicated in Tables 2-4.

${ }^{b}$ Volatile concentrations in the glass were measured by FTIR at the University of Oregon (UO) by Tuohy et al. (in preparation) or by SIMS at the Carnegie Institution of Washington (CIW) as indicated.

'Major element concentrations of the glass were measured by EPMA. The MI from Kilauea Iki and Kapoho eruptions were analyzed at the University of Oregon by Tuohy et al. (in preparation). The MI from Fuego and Seguam eruptions were analyzed at Virginia Tech.

${ }^{d}$ All MI major element and volatile concentrations in this study have been corrected for PEC either by Tuohy et al. (in preparation) or using Petrolog3 software as indicated. 
Table 2: Petrographic and Raman spectral data for MI from Kilauea iki and Kapoho.

\begin{tabular}{|c|c|c|c|c|c|c|c|c|c|c|c|c|}
\hline Sample & Number $^{a}$ & $\begin{array}{r}\text { Peak 1, } \\
\mathrm{cm}^{-1} \mathrm{~b}\end{array}$ & $\begin{array}{r}\text { Peak 2, } \\
\mathrm{cm}^{-1} \mathrm{~b}\end{array}$ & $\Delta, \mathrm{cm}^{-1}$ & $\begin{array}{c}\mathrm{CO}_{2} \text { density, } \\
\mathrm{g} / \mathrm{cm}^{3 \mathrm{c}}\end{array}$ & $\begin{array}{c}\text { MI long } \\
\text { diameter, } \\
\mu \mathrm{m}\end{array}$ & $\begin{array}{c}\text { Ml short } \\
\text { diameter, } \\
\mu \mathrm{m}\end{array}$ & $\begin{array}{c}\text { Bubble } \\
\text { diameter, } \\
\mu \mathrm{m}\end{array}$ & $\begin{array}{l}\text { Volume } \\
\text { percent } \\
\text { bubble }^{d}\end{array}$ & $\begin{array}{l}\text { Daughter } \\
\text { minerals }^{\mathrm{e}}\end{array}$ & $\mathrm{CO}_{2} \min ^{\mathrm{f}}$ & $\begin{array}{l}\text { Percent of total } \\
\mathrm{CO}_{2} \text { contained in } \\
\text { the bubble }\end{array}$ \\
\hline Kil Iki Nat R & 1_1 & 1284.78 & 1387.52 & 102.74 & 0.03 & 20 & 17 & 7 & $7 \%$ & & 939 & $76 \%$ \\
\hline Kil Iki Nat R & $1 \_2$ & 1284.72 & 1387.53 & 102.81 & 0.06 & 24 & 23 & 8 & $4 \%$ & & 948 & $76 \%$ \\
\hline Kil Iki Nat R & 1_3 & 1284.93 & 1387.59 & 102.66 & 0.01 & 14 & 12 & 5 & $6 \%$ & & 133 & $31 \%$ \\
\hline Kil Iki Nat R & 1_4 & $d$ & $d$ & & & 12 & 12 & 4 & $4 \%$ & & & \\
\hline Kil Iki Nat R & $1 \_5$ & $d$ & $d$ & & & 16 & 15 & 8 & $13 \%$ & $\mathrm{~s}$ & & \\
\hline Kil Iki Nat R & 1_6 & 1284.82 & 1387.54 & 102.72 & 0.03 & 32 & 29 & 11 & $5 \%$ & & 469 & $61 \%$ \\
\hline Kil Iki Nat R & $1 \_7$ & 1284.78 & 1387.59 & 102.80 & 0.06 & 22 & 20 & 9 & $8 \%$ & $\mathrm{~s}$ & 1716 & $85 \%$ \\
\hline Kil Iki Nat R & $1 \_8$ & $d$ & $d$ & & & 13 & 12 & 5 & $5 \%$ & & & \\
\hline Kil Iki Nat R & 1_9 & 1284.16 & 1387.15 & 102.98 & 0.13 & 37 & 37 & 26 & $34 \%$ & s & & \\
\hline Kil Iki Nat R & 1_10 & 1284.80 & 1387.57 & 102.77 & 0.04 & 57 & 55 & 18 & $4 \%$ & s & 601 & $67 \%$ \\
\hline Kil Iki Nat R & 1_11 & 1284.87 & 1387.60 & 102.74 & 0.03 & 38 & 37 & 14 & $6 \%$ & $\mathrm{~s}$ & 721 & $71 \%$ \\
\hline Kil Iki Nat R & 1_12 & 1284.93 & 1387.62 & 102.69 & 0.02 & 15 & 15 & 6 & $6 \%$ & s & 353 & $54 \%$ \\
\hline Kil Iki Nat R & 1_13 & 1286.62 & 1389.58 & 102.96 & 0.12 & 9 & 9 & 4 & $7 \%$ & & 3119 & $91 \%$ \\
\hline Kil Iki Nat R & $2 \_1$ & 1285.40 & 1388.12 & 102.72 & 0.03 & 19 & 19 & 6 & $3 \%$ & & 275 & $48 \%$ \\
\hline Kil Iki Nat R & $2 \_2$ & 1285.35 & 1388.09 & 102.75 & 0.04 & 26 & 24 & 9 & $4 \%$ & $\mathrm{~s}$ & 595 & $66 \%$ \\
\hline Kil Iki Nat R & $2 \_3$ & 1285.44 & 1388.18 & 102.74 & 0.03 & 10 & 10 & 3 & $3 \%$ & $\mathrm{~s}$ & 338 & $53 \%$ \\
\hline Kil Iki Nat R & $2 \_4$ & 1285.46 & 1388.23 & 102.77 & 0.04 & 12 & 11 & 3 & $2 \%$ & & 347 & $54 \%$ \\
\hline Kil Iki Nat R & $2 \_5$ & 1285.48 & 1388.21 & 102.74 & 0.03 & 27 & 26 & 8 & $3 \%$ & s & 320 & $52 \%$ \\
\hline Kil Iki Nat R & $2 \_6$ & 1285.55 & 1388.25 & 102.70 & 0.02 & 26 & 24 & 8 & $3 \%$ & s & 240 & $44 \%$ \\
\hline Kil Iki Nat R & $2 \_7$ & 1285.35 & 1388.18 & 102.83 & 0.07 & 29 & 29 & 9 & $3 \%$ & s & 719 & $71 \%$ \\
\hline Kil Iki Nat R & $2 \_8$ & - & 1388.38 & & & 17 & 16 & 5 & $3 \%$ & s & & \\
\hline Kil Iki Nat R & 2_9 & 1285.53 & 1388.22 & 102.68 & 0.01 & 67 & 61 & 20 & $3 \%$ & & 152 & $34 \%$ \\
\hline Kil Iki Nat R & 2_10 & 1285.58 & 1388.33 & 102.76 & 0.04 & 49 & 48 & 16 & $3 \%$ & s & 522 & $63 \%$ \\
\hline Kil Iki Nat R & 2_11 & 1285.59 & 1388.35 & 102.76 & 0.04 & 32 & 30 & 11 & $4 \%$ & & 666 & $69 \%$ \\
\hline Kil Iki Nat R & $2 \_12$ & - & - & & & 60 & 57 & 19 & $4 \%$ & & & \\
\hline Kil Iki Nat R & $3 \_1 w^{*}$ & 1285.72 & 1388.39 & 102.67 & 0.01 & 168 & 165 & 46 & $2 \%$ & $\mathrm{~s}$ & 73 & $20 \%$ \\
\hline Kil Iki Nat R & 3_2 & 1285.79 & 1388.44 & 102.65 & 0.00 & 16 & 12 & 5 & $4 \%$ & & 12 & $4 \%$ \\
\hline Kil Iki Nat R & 3_3 & 1285.64 & 1388.39 & 102.75 & 0.04 & 53 & 43 & 17 & $5 \%$ & & 707 & $70 \%$ \\
\hline Kil Iki Nat R & 3_4 & 1285.63 & 1388.34 & 102.71 & 0.02 & 41 & 31 & 11 & $4 \%$ & s & 339 & $53 \%$ \\
\hline
\end{tabular}




\begin{tabular}{|c|c|c|c|c|c|c|c|c|c|c|c|c|}
\hline Kil Iki Nat R & $3 \_5$ & 1285.70 & 1388.44 & 102.74 & 0.03 & 16 & 15 & 5 & $4 \%$ & & 510 & $63 \%$ \\
\hline Kil Iki Nat R & $3 \_6$ & 1285.63 & 1388.44 & 102.82 & 0.06 & 14 & 11 & 4 & $4 \%$ & $\mathrm{~s}$ & 1008 & $77 \%$ \\
\hline Kil Iki Nat R & $3 \_7$ & 1285.72 & 1388.49 & 102.78 & 0.05 & 17 & 14 & 5 & $4 \%$ & $\mathrm{~s}$ & 646 & $68 \%$ \\
\hline Kil Iki Nat R & 3_8 & - & - & & & 101 & 91 & 22 & $1 \%$ & $\mathrm{~s}$ & & \\
\hline Kil Iki Nat R & 3_9 & 1285.64 & 1388.41 & 102.77 & 0.05 & 58 & 50 & 17 & $3 \%$ & & 582 & $66 \%$ \\
\hline Kil Iki Nat R & 3_10 & 1284.11 & 1387.10 & 102.99 & 0.13 & 22 & 18 & 7 & $4 \%$ & & 2147 & $88 \%$ \\
\hline Kil Iki Nat R & 3_11 & 1285.74 & 1388.51 & 102.78 & 0.05 & 25 & 23 & 8 & $4 \%$ & & 679 & $69 \%$ \\
\hline Kil Iki Nat R & 3_12 & 1285.85 & 1388.61 & 102.76 & 0.04 & 17 & 12 & 4 & $2 \%$ & s & 342 & $53 \%$ \\
\hline Kil Iki Nat R & 3_13 & 1285.87 & 1388.61 & 102.74 & 0.03 & 21 & 14 & 5 & $2 \%$ & $s$ & 296 & $50 \%$ \\
\hline Kil Iki Nat R & 3_14 & 1285.78 & 1388.55 & 102.77 & 0.04 & 24 & 24 & 9 & $5 \%$ & s & 888 & $75 \%$ \\
\hline Kil Iki Nat R & 4_1 & 1283.96 & 1387.32 & 103.36 & 0.29 & 71 & 67 & 23 & $4 \%$ & s & 4289 & $93 \%$ \\
\hline Kil Iki Nat R & $4 \_2$ & 1284.24 & 1387.25 & 103.01 & 0.14 & 76 & 73 & 24 & $3 \%$ & & 1764 & $85 \%$ \\
\hline Kil Iki Nat R & $4 \_3$ & - & - & & & 68 & 62 & 15 & $1 \%$ & s & & \\
\hline Kil Iki Nat R & 4_4w* & 1284.80 & 1387.52 & 102.72 & 0.03 & 94 & 86 & 28 & $3 \%$ & s & 316 & $51 \%$ \\
\hline Kil Iki Nat R & 4_5 & 1283.82 & 1386.72 & 102.90 & 0.09 & 14 & 12 & 5 & $6 \%$ & & & \\
\hline Kil Iki Nat R & 4_6 & 1284.33 & 1387.02 & 102.69 & 0.02 & 12 & 11 & 9 & $56 \%$ & & & \\
\hline Kil Iki Nat R & 4_7 & 1283.44 & 1386.41 & 102.97 & 0.12 & 8 & 8 & 4 & $13 \%$ & & & \\
\hline Kil Iki Nat R & 4_8 & 1283.57 & 1386.59 & 103.02 & 0.14 & 11 & 11 & 8 & $41 \%$ & $s$ & & \\
\hline Kil Iki Nat R & 4_9 & 1286.67 & 1386.77 & 100.10 & 0.25 & 8 & 8 & 6 & $41 \%$ & & & \\
\hline Kil Iki Nat R & 4_10 & 1283.72 & 1386.74 & 103.02 & 0.14 & 8 & 8 & 8 & $99 \%$ & & & \\
\hline Kil Iki Nat R & 4_11 & - & - & & & 10 & 10 & 4 & $5 \%$ & & & \\
\hline Kil Iki Nat R & 4_12 & - & - & & & 16 & 16 & 5 & $4 \%$ & & & \\
\hline Kil Iki Nat R & 4_13 & - & - & & & 11 & 10 & 4 & $5 \%$ & s & & \\
\hline Kil Iki Nat R & 4_14 & - & - & & & 10 & 8 & 3 & $5 \%$ & & & \\
\hline Kil Iki Nat R & 4_15 & 1283.87 & 1386.69 & 102.82 & 0.06 & 12 & 12 & 4 & $3 \%$ & & & \\
\hline Kil Iki Nat R & 4_16 & 1283.43 & 1386.54 & 103.11 & 0.18 & 12 & 11 & 10 & $74 \%$ & & & \\
\hline Kil Iki Nat R & 5_1 & - & - & & & 32 & 25 & 8 & $3 \%$ & $\mathrm{~s}$ & & \\
\hline Kil Iki Nat R & $5 \_2$ & - & - & & & 71 & 65 & 19 & $2 \%$ & & & \\
\hline Kil Iki Nat R & 6_1 & - & - & & & 61 & 49 & 16 & $3 \%$ & $\mathrm{~s}$ & & \\
\hline Kil Iki Nat R & $6 \_2$ & $d$ & $d$ & & & 42 & 35 & 13 & $4 \%$ & & & \\
\hline Kil Iki Nat R & $6 \_3$ & - & - & & & 24 & 20 & 7 & $4 \%$ & & & \\
\hline Kil Iki Nat R & 6_4wb* & $d$ & $d$ & & & 84 & 83 & 27 & $3 \%$ & $\mathrm{~s}$ & & \\
\hline Kil Iki Nat R & $6 \_5$ & - & - & & & 31 & 24 & 7 & $2 \%$ & $\mathrm{~s}$ & & \\
\hline Kil Iki Nat R & 6_6 & - & - & & & 62 & 48 & 18 & $4 \%$ & $\mathrm{~s}$ & & \\
\hline
\end{tabular}




\begin{tabular}{|c|c|c|c|c|c|c|c|c|c|c|c|c|}
\hline Kil Iki Nat R & $6 \_7$ & 1284.74 & 1387.39 & 102.65 & 0.00 & 96 & 66 & 18 & $1 \%$ & & 8 & $2 \%$ \\
\hline Kil Iki Nat R & $6 \_8$ & 1284.86 & 1387.64 & 102.78 & 0.05 & 75 & 55 & 14 & $1 \%$ & & 222 & $43 \%$ \\
\hline Kil Iki Nat R & 6_9 & - & - & & & 10 & 8 & 3 & $3 \%$ & & & \\
\hline Kil Iki Nat R & 6_10 & - & - & & & 18 & 13 & 5 & $4 \%$ & & & \\
\hline Kil Iki Nat R & 6_11 & 1284.24 & 1387.25 & 103.01 & 0.14 & 33 & 25 & 9 & $4 \%$ & & 1853 & $86 \%$ \\
\hline Kil Iki Nat R & 6_12 & - & 1387.28 & & & 45 & 32 & 12 & $4 \%$ & $\mathrm{~s}$ & & \\
\hline Kil Iki Nat R & 6_13 & - & 1387.34 & & & 40 & 29 & 11 & $4 \%$ & $\mathrm{~s}$ & & \\
\hline Kil Iki Nat R & 6_14 & - & - & & & 23 & 15 & 6 & $4 \%$ & & & \\
\hline Kil Iki Nat R & W1* & - & - & & & 191 & 138 & 40 & $2 \%$ & & & \\
\hline Kil Iki Nat R & W2* & - & - & & & 257 & 215 & 59 & $2 \%$ & & & \\
\hline Kil Iki Nat R & W5* & - & - & & & 800 & 200 & 69 & $1 \%$ & & & \\
\hline Kil Iki Nat R & W6a* & - & - & & & 102 & 94 & 29 & $3 \%$ & $\mathrm{~s}$ & & \\
\hline Kap 8 Nat R & $1 \_1 w^{*}$ & 1285.01 & 1387.99 & 102.98 & 0.12 & 333 & 250 & 81 & $3 \%$ & & 1177 & $80 \%$ \\
\hline Kap 8 Nat R & $1 \_2$ & - & - & & & 48 & 46 & 13 & $2 \%$ & & & \\
\hline Kap 8 Nat R & $1 \_3$ & $d$ & $d$ & & & 24 & 23 & 7 & $3 \%$ & & & \\
\hline Kap 8 Nat R & $2 \_1 w^{*}$ & $d$ & $d$ & & & 394 & 245 & 101 & $4 \%$ & & & \\
\hline Kap 8 Nat R & $2 \_2$ & 1284.51 & 1387.40 & 102.89 & 0.09 & 87 & 64 & 14 & $1 \%$ & & 263 & $47 \%$ \\
\hline Kap 8 Nat R & $2 \_3$ & 1284.44 & 1387.30 & 102.87 & 0.08 & 77 & 77 & 31 & $6 \%$ & & 2033 & $87 \%$ \\
\hline Kap 8 Nat R & $2 \_4$ & 1284.47 & 1387.30 & 102.84 & 0.07 & 49 & 42 & 19 & $8 \%$ & & 2095 & $87 \%$ \\
\hline Kap 8 Nat R & $2 \_5$ & 1284.24 & 1387.26 & 103.02 & 0.14 & 9 & 8 & 3 & $6 \%$ & & 3062 & $91 \%$ \\
\hline Kap 8 Nat R & $2 \_6$ & 1284.37 & 1387.26 & 102.88 & 0.09 & 16 & 12 & 5 & $4 \%$ & $\mathrm{~s}$ & 1471 & $83 \%$ \\
\hline Kap 8 Nat R & $2 \_7$ & 1284.07 & 1387.12 & 103.05 & 0.15 & 10 & 8 & 3 & $2 \%$ & c & 1344 & $82 \%$ \\
\hline Kap 8 Nat R & $2 \_8$ & 1285.10 & 1388.19 & 103.09 & 0.17 & 29 & 25 & 7 & $2 \%$ & s, C & 1151 & $79 \%$ \\
\hline Kap 8 Nat R & 2_9 & 1284.21 & 1387.20 & 102.98 & 0.13 & 95 & 52 & 22 & $4 \%$ & $\mathrm{~s}$ & 1939 & $87 \%$ \\
\hline Kap 8 Nat R & 2_10 & 1284.15 & 1387.10 & 102.95 & 0.11 & 93 & 59 & 22 & $3 \%$ & & 1368 & $82 \%$ \\
\hline Kap 8 Nat R & 2_11 & 1284.43 & 1387.35 & 102.92 & 0.10 & 8 & 8 & 3 & $6 \%$ & $s, C$ & 2571 & $90 \%$ \\
\hline Kap 8 Nat R & 2_12 & 1284.23 & 1387.22 & 102.98 & 0.13 & 9 & 8 & 3 & $7 \%$ & $S, C$ & 3421 & $92 \%$ \\
\hline Kap 8 Nat R & $2 \_13$ & 1284.20 & 1387.21 & 103.00 & 0.13 & 16 & 15 & 6 & $5 \%$ & & 2650 & $90 \%$ \\
\hline Kap 8 Nat R & 2_14 & 1284.29 & 1387.16 & 102.87 & 0.08 & 11 & 7 & 3 & $8 \%$ & & 2579 & $90 \%$ \\
\hline Kap 8 Nat R & 2_15 & 1284.16 & 1387.07 & 102.91 & 0.10 & 8 & 7 & 3 & $8 \%$ & & 2997 & $91 \%$ \\
\hline Kap 8 Nat R & 3_1 $w^{*}$ & 1285.74 & 1388.50 & 102.76 & 0.04 & 175 & 162 & 56 & $4 \%$ & & 592 & $66 \%$ \\
\hline Kap 8 Nat R & $3 \_2$ & 1285.90 & 1388.63 & 102.74 & 0.03 & 46 & 45 & 15 & $4 \%$ & & 462 & $61 \%$ \\
\hline Kap 8 Nat R & $3 \_3$ & 1285.86 & 1388.56 & 102.71 & 0.02 & 12 & 11 & 3 & $3 \%$ & & 222 & $42 \%$ \\
\hline Kap 8 Nat R & 3_4 & $d$ & $\mathrm{~d}$ & & & 12 & 12 & 4 & $4 \%$ & & & \\
\hline
\end{tabular}




\begin{tabular}{|c|c|c|c|c|c|c|c|c|c|c|c|c|}
\hline Kap 8 Nat R & $3 \_5$ & 1285.12 & 1388.08 & 102.96 & 0.12 & 13 & 13 & 10 & $49 \%$ & & & \\
\hline Kap 8 Nat R & $3 \_6$ & 1285.13 & 1388.09 & 102.96 & 0.12 & 17 & 17 & 16 & $87 \%$ & & & \\
\hline Kap 8 Nat R & $3 \_7$ & 1285.99 & 1388.59 & 102.61 & low & 14 & 11 & 4 & $3 \%$ & & & \\
\hline Kap 8 Nat R & $3 \_8$ & 1285.68 & 1388.44 & 102.76 & 0.04 & 79 & 70 & 23 & $3 \%$ & & 465 & $61 \%$ \\
\hline Kap 8 Nat R & 3_9 & 1285.16 & 1388.08 & 102.92 & 0.10 & 21 & 21 & 8 & $6 \%$ & & 2204 & $88 \%$ \\
\hline Kap 8 Nat R & 3_10 & 1285.15 & 1388.07 & 102.92 & 0.10 & 23 & 23 & 9 & $6 \%$ & & 2174 & $88 \%$ \\
\hline Kap 8 Nat R & 3_11 & 1285.16 & 1388.07 & 102.92 & 0.10 & 22 & 22 & 18 & $59 \%$ & & & \\
\hline Kap 8 Nat R & 3_12 & - & - & & & 21 & 21 & 6 & $3 \%$ & $\mathrm{~s}$ & & \\
\hline Kap 8 Nat R & 4_1w* & 1284.72 & 1387.88 & 103.16 & 0.20 & 223 & 145 & 83 & $12 \%$ & & & $97 \%$ \\
\hline Kap 8 Nat R & $4 \_2$ & - & - & & & 13 & 11 & 5 & $10 \%$ & & & \\
\hline Kap 8 Nat R & $4 \_3$ & 1284.91 & 1387.91 & 103.01 & 0.14 & 21 & 19 & 9 & $9 \%$ & & 4633 & $94 \%$ \\
\hline Kap 8 Nat R & 4_4 & 1285.13 & 1388.00 & 102.87 & 0.08 & 47 & 29 & 13 & $6 \%$ & & 1823 & $86 \%$ \\
\hline Kap 8 Nat R & 4_5 & 1285.42 & 1388.20 & 102.78 & 0.05 & 33 & 30 & 11 & $4 \%$ & & 793 & $73 \%$ \\
\hline Kap 8 Nat R & 4_6 & 1285.38 & 1388.17 & 102.79 & 0.05 & 25 & 20 & 8 & $5 \%$ & $\mathrm{~s}$ & 942 & $76 \%$ \\
\hline Kap 8 Nat R & 4_7 & 1285.27 & 1388.13 & 102.86 & 0.08 & 20 & 16 & 7 & $7 \%$ & & 2024 & $87 \%$ \\
\hline Kap 8 Nat R & $4 \_8$ & 1285.30 & 1388.16 & 102.86 & 0.08 & 20 & 16 & 6 & $5 \%$ & $\mathrm{~s}$ & 1524 & $84 \%$ \\
\hline Kap 8 Nat R & 4_9 & 1285.21 & 1388.20 & 103.00 & 0.13 & 18 & 16 & 7 & $8 \%$ & & 3926 & $93 \%$ \\
\hline Kap 8 Nat R & 4_10 & 1285.20 & 1388.10 & 102.90 & 0.09 & 15 & 14 & 6 & $8 \%$ & & 2847 & $90 \%$ \\
\hline Kap 8 Nat R & 4_11 & 1285.27 & 1388.13 & 102.86 & 0.08 & 12 & 12 & 5 & $8 \%$ & & 2323 & $89 \%$ \\
\hline Kap 8 Nat R & 4_12 & 1285.21 & 1388.23 & 103.02 & 0.14 & 12 & 9 & 5 & $10 \%$ & & 5385 & $95 \%$ \\
\hline Kap 8 Nat R & $5 \_1 w^{*}$ & - & - & & & 122 & 109 & 37 & $4 \%$ & $\mathrm{~s}$ & & \\
\hline Kap 8 Nat R & $5 \_2 w^{*}$ & - & - & & & 177 & 142 & 50 & $4 \%$ & $\mathrm{~s}$ & & \\
\hline Kap 8 Nat R & $5 \_3$ & 1284.89 & 1387.80 & 102.91 & 0.10 & 47 & 42 & 17 & $7 \%$ & $\mathrm{~s}$ & 2469 & $89 \%$ \\
\hline Kap 8 Nat R & 5_4 & 1284.33 & 1387.47 & 103.14 & 0.19 & 42 & 36 & 22 & $19 \%$ & & & \\
\hline Kap 8 Nat R & 5_5 & 1285.17 & 1387.96 & 102.79 & 0.05 & 36 & 28 & 9 & $3 \%$ & $\mathrm{~s}$ & 536 & $64 \%$ \\
\hline Kap 8 Nat R & 5_6 & 1284.92 & 1387.82 & 102.90 & 0.09 & 22 & 18 & 5 & $2 \%$ & $\mathrm{~s}$ & 529 & $64 \%$ \\
\hline Kap 8 Nat R & 5_7 & 1285.08 & 1387.91 & 102.84 & 0.07 & 25 & 15 & 6 & $4 \%$ & $\mathrm{~s}$ & 1093 & $78 \%$ \\
\hline Kap 8 Nat R & 5_8 & 1285.04 & 1387.95 & 102.91 & 0.10 & 17 & 14 & 6 & $5 \%$ & $\mathrm{~s}$ & 1929 & $87 \%$ \\
\hline Kap 8 Nat R & 5_9 & 1284.81 & 1387.78 & 102.97 & 0.12 & 12 & 12 & 5 & $8 \%$ & & 3785 & $93 \%$ \\
\hline Kap 8 Nat R & 5_10 & 1284.85 & 1387.82 & 102.97 & 0.12 & 12 & 10 & 4 & $7 \%$ & & 3182 & $91 \%$ \\
\hline Kap 8 Nat R & 5_11 & 1284.98 & 1387.91 & 102.93 & 0.10 & 9 & 7 & 4 & $10 \%$ & & 4061 & $93 \%$ \\
\hline Kap 8 Nat R & 5_12 & 1285.00 & 1387.90 & 102.90 & 0.09 & 8 & 7 & 3 & $8 \%$ & & 2800 & $90 \%$ \\
\hline Kap 8 Nat R & $6 \_1 w^{*}$ & 1284.78 & 1387.64 & 102.86 & 0.08 & 501 & 296 & 93 & $2 \%$ & & 531 & $64 \%$ \\
\hline Kap 8 Nat R & 6_2 & 1284.76 & 1387.67 & 102.91 & 0.10 & 57 & 48 & 20 & $6 \%$ & & 2374 & $89 \%$ \\
\hline
\end{tabular}




\begin{tabular}{|c|c|c|c|c|c|c|c|c|c|c|c|c|}
\hline Kap 8 Nat R & 6_3 & 1284.64 & 1387.58 & 102.94 & 0.11 & 93 & 61 & 31 & $9 \%$ & & 3742 & $93 \%$ \\
\hline Kap 8 Nat R & 6_4 & 1284.78 & 1387.62 & 102.84 & 0.07 & 125 & 99 & 34 & $3 \%$ & & 844 & $74 \%$ \\
\hline Kap 8 Nat R & $6 \_5$ & 1284.84 & 1387.72 & 102.88 & 0.09 & 45 & 44 & 12 & $2 \%$ & & 564 & $65 \%$ \\
\hline Kap 8 Nat R & W2a* & - & - & & & 201 & 129 & 61 & $7 \%$ & & & \\
\hline Kap 8 Nat R & W3b* & $d$ & $d$ & & & 343 & 275 & 87 & $3 \%$ & & & \\
\hline Kap 8 Nat R & W5c* & - & - & & & 166 & 124 & 56 & $7 \%$ & s & & \\
\hline Kap 8 Nat R & W7* & 1284.80 & 1387.69 & 102.89 & 0.09 & 70 & 60 & 23 & $5 \%$ & & 1708 & $85 \%$ \\
\hline
\end{tabular}

${ }^{\text {a }}$ Samples for which the volatile content of the glass has been analyzed are indicated with an asterisk $(*)$.

${ }^{b}$ Fermi diad peak positions determined by peak fitting of Raman spectra collected from MI (see methods) at Virginia Tech. Values marked as "-" indicate that $\mathrm{CO}_{2}$ was not detected ; values marked as "d" indicate that $\mathrm{CO}_{2}$ was detected, but the quality of the Raman spectra did not allow the peak splitting and thus $\mathrm{CO}_{2}$ density to be quantified (see text).

'values marked as "low" indicate that the density could not be quantified with the Fall et al. (2011) equation for the measured peak separation (see text).

${ }^{\mathrm{d}}$ The ratio of the volume of the bubble to the total MI volume was calculated by treating the bubble as a sphere and the MI as an oblate spheroid (see text).

${ }^{\mathrm{e}} \mathrm{MI}$ contain a chromite spinel (?)("s") or carbonates ("c") in addition to a bubble as indicated (see text).

${ }^{\mathrm{f}}$ The minimum amount of $\mathrm{CO}_{2}$ in the MI. This is calculated by Raman analysis of the bubble and by using a value of 0 ppm for the $\mathrm{CO}_{2}$ contained in the glass.

${ }^{\mathrm{g}}$ Percent of the total $\mathrm{CO}_{2}$ in the $\mathrm{Ml}$ that is contained in the bubble assuming a melt (glass) that contains 300 ppm $\mathrm{CO}_{2}$ (see text) 
Table 3: Petrographic and Raman spectral data for MI from Fuego.

\begin{tabular}{|c|c|c|c|c|c|c|c|c|c|c|c|c|}
\hline Sample & Number $^{a}$ & $\begin{array}{l}\text { Peak 1, } \\
\mathrm{cm}^{-1 \mathrm{~b}}\end{array}$ & $\begin{array}{l}\text { Peak 2, } \\
\mathrm{cm}^{-1 ~ b}\end{array}$ & $\Delta, \mathrm{cm}^{-1}$ & $\begin{array}{l}\mathrm{CO}_{2} \\
\text { density, } \\
\mathrm{g} / \mathrm{cm}^{3 \mathrm{c}}\end{array}$ & 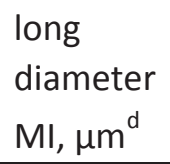 & $\begin{array}{l}\text { short } \\
\text { diameter } \\
\mathrm{MI}, \mu \mathrm{m}^{\mathrm{d}}\end{array}$ & $\begin{array}{l}\text { Bubble } \\
\text { diameter, } \\
\mu \mathrm{m}^{\mathrm{d}}\end{array}$ & $\begin{array}{l}\text { Volume } \\
\text { percent } \\
\text { bubble }\end{array}$ & $\begin{array}{l}\text { daughter } \\
\text { minerals }^{\mathrm{e}}\end{array}$ & $\mathrm{CO}_{2} \min ^{\mathrm{f}}$ & $\begin{array}{c}\text { Percent of total } \\
\mathrm{CO}_{2} \text { contained in } \\
\text { the bubble }\end{array}$ \\
\hline Fuego & 5.1 & 1285.28 & 1388.58 & 103.30 & 0.26 & 19 & 19 & 7 & $4 \%$ & & 4076 & $85 \%$ \\
\hline Fuego & 5.2 & - & - & & & 24 & n.r. & 7 & $2 \%$ & $\mathrm{~s}$ & & \\
\hline Fuego & $5.3^{*}$ & 1285.18 & 1387.92 & 102.75 & 0.04 & 56 & 47 & 15 & $2 \%$ & $\mathrm{~S}, \mathrm{C}$ & 293 & $30 \%$ \\
\hline Fuego & 6.1 & 1286.06 & 1389.09 & 103.03 & 0.15 & 58 & 58 & 13 & $1 \%$ & S & 577 & $45 \%$ \\
\hline Fuego & 6.2 & 1286.06 & 1388.96 & 102.90 & 0.09 & 34 & 34 & 8 & $2 \%$ & & 523 & $43 \%$ \\
\hline Fuego & 6.3 & - & - & & & 19 & n.r. & 7 & $5 \%$ & $S, C$ & & \\
\hline Fuego & 6.6 & - & - & & & 20 & 15 & 6 & $4 \%$ & $S, C$ & & \\
\hline Fuego & 7.1 & - & - & & & 21 & n.r. & 5 & $1 \%$ & & & \\
\hline Fuego & 7.2 & - & - & & & 35 & n.r. & 8 & $1 \%$ & & & \\
\hline Fuego & 7.6 & - & - & & & 21 & 19 & 6 & $2 \%$ & $\mathrm{~s}$ & & \\
\hline Fuego & 7.7 & - & - & & & 33 & 32 & 8 & $2 \%$ & $S$ & & \\
\hline Fuego & 7.4 & - & - & & & 56 & 56 & 12 & $1 \%$ & C & & \\
\hline Fuego & 7.3 & - & - & & & 27 & 23 & 8 & $3 \%$ & $\mathrm{~s}$ & & \\
\hline Fuego & 8.1 & - & - & & & 11 & n.r. & 3 & $2 \%$ & $S$ & & \\
\hline Fuego & 8.2 & - & - & & & 24 & n.r. & 5 & $1 \%$ & $S, C$ & & \\
\hline Fuego & 8.3 & - & - & & & 72 & 68 & 18 & $2 \%$ & & & \\
\hline Fuego & 8.4 & - & - & & & n.r. & n.r. & n.r. & n.r. & C & & \\
\hline Fuego & 9.1 & - & - & & & n.r. & n.r. & n.r. & n.r. & $S, C$ & & \\
\hline Fuego & $9.2^{*}$ & 1284.58 & 1387.55 & 102.97 & 0.12 & 98 & 82 & 26 & $2 \%$ & $S$ & 1063 & $60 \%$ \\
\hline Fuego & 10.1 & - & - & & & 79 & 65 & 19 & $2 \%$ & $S, C$ & & \\
\hline Fuego & 10.2 & - & - & & & n.r. & n.r. & n.r. & n.r. & $S, C$ & & \\
\hline Fuego & $11.1^{*}$ & 1283.92 & 1386.96 & 103.04 & 0.15 & 105 & 86 & 29 & $3 \%$ & $\mathrm{~S}, \mathrm{C}$ & 1616 & $70 \%$ \\
\hline Fuego & 11.2 & - & - & & & 10 & 7 & 3 & $4 \%$ & 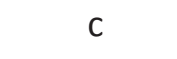 & & \\
\hline Fuego & 12.1 & - & - & & & n.r. & n.r. & n.r. & n.r. & $S, C$ & & \\
\hline Fuego & 12.2 & - & - & & & n.r. & n.r. & n.r. & n.r. & C & & \\
\hline Fuego & $12.3^{*}$ & $d$ & $d$ & & & 132 & 112 & 38 & $3 \%$ & $\mathrm{~S}, \mathrm{C}$ & & \\
\hline Fuego & 13.1 & - & - & & & 57 & 52 & 16 & $3 \%$ & & & \\
\hline Fuego & 13.2 & - & - & & & 13 & 11 & 3 & $2 \%$ & s & & \\
\hline Fuego & 14.1 & 1285.09 & 1388.07 & 102.98 & 0.13 & 52 & 41 & 15 & $3 \%$ & $\mathrm{~s}$ & 1558 & $69 \%$ \\
\hline Fuego & $15.1^{*}$ & $d$ & $d$ & & & 144 & 139 & 37 & $2 \%$ & & & \\
\hline
\end{tabular}




\begin{tabular}{|c|c|c|c|c|c|c|c|c|c|c|c|c|}
\hline Fuego & $19.1^{*}$ & 1283.91 & 1387.00 & 103.09 & 0.17 & 63 & 52 & 18 & $3 \%$ & $s$ & 1871 & $73 \%$ \\
\hline Fuego & 19.2 & - & - & & & 32 & 31 & 11 & $4 \%$ & $\mathrm{~s}, \mathrm{C}$ & & \\
\hline Fuego & $10.3 a$ & 1285.14 & 1388.23 & 103.09 & 0.17 & 11 & 10 & 3 & $2 \%$ & s & 1547 & $69 \%$ \\
\hline Fuego & $10.3 b$ & 1285.14 & 1387.98 & 102.84 & 0.07 & 19 & 17 & 6 & $4 \%$ & s & 1125 & $62 \%$ \\
\hline Fuego & $10.3 c$ & - & - & & & n.r. & n.r. & & & S, c & & \\
\hline
\end{tabular}

${ }^{\mathrm{a}}$ Samples for which the volatile content of the glass has been analyzed are indicated with an asterisk $(*)$.

${ }^{\mathrm{b}}$ Fermi diad peak positions determined by peak fitting of Raman spectra collected from MI (see methods) at Virginia Tech. Values marked as "-" indicate that $\mathrm{CO}_{2}$ was not detected ; values marked as "d" indicate that $\mathrm{CO}_{2}$ was detected, but the quality of the Raman spectra did not allow the peak splitting and thus $\mathrm{CO}_{2}$ density to be quantified (see text).

'values marked as "low" indicate that the density could not be quantified with the Fall et al. (2011) equation for the measured peak separation (see text). dimensions listed as "n.r." indicate dimensions that were not recorded. Where only one MI dimension is reported, the volume percent is calculated treating the $\mathrm{Ml}$ as a sphere; in these cases, reconstructed $\mathrm{CO}_{2}$ concentrations were not calculated.

${ }^{\mathrm{e}} \mathrm{Ml}$ contain a chromite spinel (?)("s") or carbonates ("c") in addition to a bubble as indicated (see text).

${ }^{\mathrm{f}}$ The minimum amount of $\mathrm{CO}_{2}$ in the MI. This is calculated by Raman analysis of the bubble and by using a value of 0 ppm for the $\mathrm{CO}_{2}$ contained in the glass.

${ }^{\mathrm{g}}$ Percent of the total $\mathrm{CO}_{2}$ in the $\mathrm{Ml}$ that is contained in the bubble assuming a melt (glass) that contains 700 ppm $\mathrm{CO}_{2}$ (see text) 
Table 4: Petrographic and Raman spectral data for MI from Seguam.

\begin{tabular}{|c|c|c|c|c|c|c|c|c|c|c|c|c|}
\hline Sample & Number ${ }^{a}$ & $\begin{array}{l}\text { Peak 1, } \\
\mathrm{cm}^{-1} \mathrm{~b}\end{array}$ & $\begin{array}{l}\text { Peak 2, } \\
\mathrm{cm}^{-1} \mathrm{~b}\end{array}$ & $\Delta, \mathrm{cm}^{-1}$ & $\begin{array}{l}\mathrm{CO}_{2} \\
\text { density, } \\
\mathrm{g} / \mathrm{cm}^{3 \mathrm{c}}\end{array}$ & 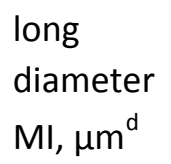 & $\begin{array}{l}\text { short } \\
\text { diameter } \\
\mathrm{MI}, \mu \mathrm{m}^{\mathrm{d}}\end{array}$ & $\begin{array}{l}\text { Bubble } \\
\text { diameter, } \\
{\mu \mathrm{m}^{\mathrm{d}}}^{\mathrm{d}}\end{array}$ & $\begin{array}{l}\text { Volume } \\
\text { percent } \\
\text { bubble }^{d}\end{array}$ & $\begin{array}{l}\text { daughter } \\
\text { minerals }^{\mathrm{e}}\end{array}$ & $\mathrm{CO}_{2} \min ^{\mathrm{e}}$ & $\begin{array}{l}\text { Percent of total } \\
\mathrm{CO}_{2} \text { contained in } \\
\text { the bubble }\end{array}$ \\
\hline Seguam & $2.1^{*}$ & 1285.60 & 1388.26 & 102.67 & 0.01 & 106 & 93 & 27 & $2 \%$ & & 55 & $10 \%$ \\
\hline Seguam & 3.1 & - & - & & & 22 & 20 & 5 & $2 \%$ & $b$ & & \\
\hline Seguam & 3.2 & - & - & & & 15 & 13 & 4 & $2 \%$ & $b$ & & \\
\hline Seguam & 4.1 & - & - & & & 17 & 16 & 6 & $6 \%$ & $\mathrm{~b}$ & & \\
\hline Seguam & 4.2 & - & - & & & 21 & 15 & 6 & $5 \%$ & $c, b$ & & \\
\hline Seguam & 5.1 & $d$ & $d$ & & & 73 & 64 & 20 & $3 \%$ & & & \\
\hline Seguam & $5.2^{*}$ & 1285.39 & 1388.12 & 102.73 & 0.03 & 135 & 117 & 38 & $3 \%$ & & 303 & $38 \%$ \\
\hline Seguam & 5.3 & - & - & & & 18 & 14 & 5 & $3 \%$ & & & \\
\hline Seguam & $6.1^{*}$ & 1285.34 & 1388.11 & 102.77 & 0.04 & 159 & 133 & 40 & $2 \%$ & & 367 & $42 \%$ \\
\hline Seguam & 7.1 & - & - & & & 176 & 127 & 36 & $2 \%$ & $c, b$ & & \\
\hline Seguam & 7.2 & - & - & & & 11 & 9 & 3 & $5 \%$ & & & \\
\hline Seguam & 7.3 & - & - & & & 28 & 22 & 7 & $3 \%$ & & & \\
\hline Seguam & 7.4 & - & - & & & 28 & 26 & 8 & $3 \%$ & & & \\
\hline Seguam & $7.5^{*}$ & 1285.31 & 1388.00 & 102.69 & 0.02 & 114 & 84 & 31 & $4 \%$ & & 223 & $31 \%$ \\
\hline Seguam & 8.1 & $d$ & $d$ & & & 17 & 17 & 5 & $3 \%$ & & & \\
\hline Seguam & 8.2 & $d$ & $d$ & & & 43 & 40 & 12 & $3 \%$ & & & \\
\hline Seguam & $8.3^{*}$ & 1285.31 & 1388.00 & 102.69 & 0.01 & 138 & 136 & 41 & $3 \%$ & & 137 & $21 \%$ \\
\hline Seguam & 8.4 & - & - & & & 68 & 62 & 19 & $3 \%$ & & & \\
\hline Seguam & $9.1^{*}$ & $d$ & $d$ & & & 88 & 82 & 29 & $4 \%$ & $b$ & & \\
\hline Seguam & $10.1^{*}$ & 1285.64 & 1388.34 & 102.70 & 0.02 & 82 & 66 & 20 & $2 \%$ & & 166 & $25 \%$ \\
\hline Seguam & 10.2 & - & - & & & 28 & 25 & 7 & $2 \%$ & $b$ & & \\
\hline Seguam & 10.3 & - & - & & & 37 & 17 & 8 & $5 \%$ & & & \\
\hline Seguam & 11.1 & $d$ & $d$ & & & 23 & 21 & 8 & $5 \%$ & & & \\
\hline Seguam & 11.2 & - & - & & & 9 & 8 & 3 & $4 \%$ & & & \\
\hline Seguam & 11.3 & - & - & & & 15 & 15 & 5 & $3 \%$ & & & \\
\hline Seguam & 11.4 & - & - & & & 9 & 9 & 3 & $4 \%$ & & & \\
\hline Seguam & 12.1 & $d$ & $d$ & & & 100 & 94 & 24 & $2 \%$ & & & \\
\hline Seguam & $13.1^{*}$ & 1285.43 & 1388.19 & 102.77 & 0.04 & 88 & 87 & 28 & $3 \%$ & & 547 & $52 \%$ \\
\hline Seguam & 14.1 & - & - & & & 89 & 75 & 24 & $3 \%$ & & & \\
\hline Seguam & $15.1^{*}$ & 1285.49 & 1388.32 & 102.83 & 0.07 & 82 & 59 & 20 & $3 \%$ & & 707 & $59 \%$ \\
\hline
\end{tabular}




\begin{tabular}{|c|c|c|c|c|c|c|c|c|c|c|c|c|}
\hline Seguam & $16.1^{*}$ & 1285.47 & 1388.16 & 102.69 & 0.01 & 126 & 105 & 34 & $3 \%$ & & 144 & $22 \%$ \\
\hline Seguam & 18.1 & 1285.45 & 1388.15 & 102.70 & 0.02 & 31 & 28 & 9 & $3 \%$ & $b$ & 245 & $33 \%$ \\
\hline Seguam & 19.1 & - & - & & & 61 & 55 & 11 & $1 \%$ & & & \\
\hline Seguam & $20 *$ & - & - & & & 122 & 93 & 22 & $1 \%$ & & & \\
\hline Seguam & $22.1^{*}$ & 1285.18 & 1387.97 & 102.80 & 0.05 & 69 & 61 & 21 & $3 \%$ & & 672 & $57 \%$ \\
\hline Seguam & $23.1^{*}$ & 1285.32 & 1388.01 & 102.69 & 0.01 & 117 & 93 & 28 & $2 \%$ & & 121 & $19 \%$ \\
\hline Seguam & 23.2 & - & - & & & 35 & 31 & 10 & $3 \%$ & & & \\
\hline Seguam & 23.3 & - & - & & & 15 & 12 & 4 & $3 \%$ & c & & \\
\hline Seguam & 24.1 & - & - & & & 15 & 14 & 3 & $1 \%$ & & & \\
\hline Seguam & 24.2 & - & - & & & 28 & 19 & 8 & $5 \%$ & & & \\
\hline Seguam & 24.3 & - & - & & & n.r. & n.r. & n.r. & n.r. & & & \\
\hline Seguam & 24.4 & - & - & & & 23 & 17 & 6 & $3 \%$ & & & \\
\hline Seguam & 24.5 & - & - & & & 16 & 12 & 4 & $3 \%$ & & & \\
\hline Seguam & 24.6 & - & - & & & 30 & 22 & 7 & $3 \%$ & & & \\
\hline Seguam & 24.7 & - & - & & & 8 & 7 & 2 & $3 \%$ & & & \\
\hline Seguam & 24.8 & - & - & & & 26 & 21 & 7 & $3 \%$ & & & \\
\hline Seguam & $24.9 *$ & 1285.68 & 1388.38 & 102.69 & 0.02 & 80 & 49 & 8 & $0 \%$ & & 14 & $3 \%$ \\
\hline Seguam & 24.10 & - & - & & & 49 & 42 & 13 & $3 \%$ & & & \\
\hline
\end{tabular}

${ }^{a}$ Samples for which the volatile content of the glass has been analyzed are indicated with an asterisk $(*)$.

${ }^{a}$ Fermi diad peak positions determined by peak fitting of Raman spectra collected from MI (see methods) at Virginia Tech. Values marked as "-" indicate that $\mathrm{CO}_{2}$ was not detected ; values marked as "d" indicate that $\mathrm{CO}_{2}$ was detected, but the quality of the Raman spectra did not allow the peak splitting and thus $\mathrm{CO}_{2}$ density to be quantified (see text).

${ }^{b}$ values marked as "low" indicate that the density could not be quantified with the Fall et al. (2011) equation for the measured peak separation (see text).

cdimensions listed as "n.r." indicate dimensions that were not recorded.

${ }^{\mathrm{d}} \mathrm{MI}$ indicated with a "s" contain a chromite spinel (?) in addition to a bubble. MI indicated with a "b" or "c" indicate that carbonates were present at the bubble-glass interface. "b" indicates that bright carbonate minerals were visible in reflected light, and "c" indicates that carbonate was detected by Raman spectroscopy (see text).

${ }^{\mathrm{e}}$ The minimum amount of $\mathrm{CO}_{2}$ in the $\mathrm{Ml}$ calculated by Raman analysis of the bubble and by using a value of 0 ppm for the $\mathrm{CO}_{2}$ contained in the glass.

${ }^{\mathrm{f}}$ Percent of the total $\mathrm{CO}_{2}$ in the $\mathrm{Ml}$ that is contained in the bubble assuming a melt (glass) that contains 500 ppm $\mathrm{CO}_{2}$ (see text) 
Table 5: reconstructed $\mathrm{CO} 2$ values and calculated pressures

\begin{tabular}{|c|c|c|c|c|c|c|c|c|c|c|c|c|c|c|}
\hline Sample & Number ${ }^{a}$ & $\mathrm{H}_{2} \mathrm{O}, w t \%^{b}$ & $\begin{array}{c}\mathrm{CO}_{2} \\
\text { (glass), } \\
\text { ppm }^{\mathrm{b}}\end{array}$ & $\begin{array}{l}\mathrm{P} \text { (glass), } \\
\text { kbar }^{c}\end{array}$ & $\begin{array}{c}\text { Depth } \\
\text { (glass), } \\
\mathrm{km}^{\mathrm{d}}\end{array}$ & $\begin{array}{c}\% \text { of } \mathrm{CO}_{2} \text { in } \\
\text { bubble }\end{array}$ & $\begin{array}{c}\% \text { of } \mathrm{H}_{2} \mathrm{O} \text { in } \\
\text { bubble }^{f}\end{array}$ & $\begin{array}{l}\text { Estimated percent } \\
\text { of total } \mathrm{CO}_{2} \\
\text { contained in the } \\
\text { bubble }\end{array}$ & $\begin{array}{c}\mathrm{CO}_{2} \text { (glass + } \\
\text { bubble) } \\
\text { ppm }^{\mathrm{g}}\end{array}$ & Error, & , ppm ${ }^{h}$ & $\begin{array}{c}\text { P (glass + } \\
\text { bubble), } \\
\text { bars }^{c}\end{array}$ & $\begin{array}{c}\text { depth } \\
\text { (glass + } \\
\text { bubble), } \\
\text { km }^{\mathrm{d}}\end{array}$ & $\begin{array}{c}\mathrm{CO}_{2} \text { (glass }+ \text { ideal } \\
\text { gas), bars }\end{array}$ \\
\hline Fuego & $5.3^{*}$ & 4.03 & 189 & 1.9 & 7 & $63 \%$ & $1 \%$ & $30 \%$ & 513 & +46 & -164 & 2.6 & 9 & 1110 \\
\hline Fuego & 9.2 & 4.36 & 501 & 2.8 & 10 & $70 \%$ & $2 \%$ & $60 \%$ & 1684 & +192 & -560 & 4.8 & 18 & 3093 \\
\hline Fuego & $11.1^{*}$ & 4.29 & 511 & 2.7 & 10 & $78 \%$ & $3 \%$ & $70 \%$ & 2334 & +288 & -871 & 5.8 & 21 & 3857 \\
\hline Fuego & 19.1 & 4.11 & 488 & 2.6 & 9 & $81 \%$ & $4 \%$ & $73 \%$ & 2598 & +287 & -1054 & 6.0 & 22 & 3773 \\
\hline Seguam & 2.1 & 3.91 & 100 & 1.6 & 6 & $35 \%$ & $0 \%$ & $10 \%$ & 159 & +10 & -25 & 1.8 & 6 & 536 \\
\hline Seguam & 5.2 & 3.79 & 191 & 1.8 & 6 & $61 \%$ & $1 \%$ & $38 \%$ & 508 & +57 & -122 & 2.4 & 9 & 1303 \\
\hline Seguam & 6.1 & 3.90 & 114 & 1.7 & 6 & $62 \%$ & $1 \%$ & $42 \%$ & 299 & +30 & -70 & 2.1 & 7 & 369 \\
\hline Seguam & 7.5 & 3.69 & 179 & 1.7 & 6 & $55 \%$ & $1 \%$ & $31 \%$ & 407 & +36 & -118 & 2.2 & 8 & 1518 \\
\hline Seguam & 8.3 & 4.00 & 181 & 1.9 & 7 & $46 \%$ & $1 \%$ & $21 \%$ & 344 & +28 & -66 & 2.2 & 8 & 1271 \\
\hline Seguam & 10.1 & 3.87 & 502 & 2.5 & 9 & $24 \%$ & $0 \%$ & $25 \%$ & 656 & +36 & -79 & 2.8 & 10 & 2708 \\
\hline Seguam & 13.1 & 4.50 & 200 & 2.3 & 8 & $79 \%$ & $3 \%$ & $52 \%$ & 802 & +94 & -282 & 3.4 & 13 & 1769 \\
\hline Seguam & 15.1 & 3.81 & 48 & 1.5 & 5 & $93 \%$ & $10 \%$ & $59 \%$ & 756 & +107 & -397 & 2.9 & 11 & 316 \\
\hline Seguam & 16.1 & 4.02 & 202 & 1.9 & 7 & $29 \%$ & $0 \%$ & $22 \%$ & 293 & +13 & -41 & 2.1 & 8 & 855 \\
\hline Seguam & 22.1 & 4.19 & 224 & 2.1 & 8 & $75 \%$ & $2 \%$ & $57 \%$ & 896 & +102 & -305 & 3.4 & 12 & 1708 \\
\hline Seguam & 23.1 & 3.90 & 197 & 1.8 & 7 & $38 \%$ & $0 \%$ & $19 \%$ & 322 & +20 & -60 & 2.1 & 8 & 1089 \\
\hline Seguam & 24.9 & 2.92 & 55 & 1.0 & 3 & $18 \%$ & $0 \%$ & $3 \%$ & 77 & +1 & -9 & 1.0 & 4 & 80 \\
\hline Kil Iki Nar R & $3 w$ & 0.30 & 78 & 0.2 & 1 & $48 \%$ & $0 \%$ & $20 \%$ & 151 & +35 & -34 & 0.3 & 1 & 734 \\
\hline Kil Iki Nar R & $4 w$ & 0.19 & 230 & 0.5 & 2 & $63 \%$ & $0 \%$ & $51 \%$ & 624 & +116 & -183 & 1.3 & 5 & 3883 \\
\hline Kap 8 Nat R & $1 w$ & 0.96 & 140 & 0.4 & 1 & $89 \%$ & $2 \%$ & $80 \%$ & 1318 & +239 & -599 & 2.7 & 10 & 1528 \\
\hline Kap 8 Nat R & $3 w$ & 0.63 & 152 & 0.4 & 1 & $80 \%$ & $0 \%$ & $66 \%$ & 744 & +239 & -281 & 1.6 & 6 & 2435 \\
\hline Kap 8 Nat R & $4 w$ & 0.77 & 320 & 0.7 & 3 & $97 \%$ & $5 \%$ & $97 \%$ & 10607 & +1820 & -5967 & 12.7 & 46 & 17289 \\
\hline Kap 8 Nat R & $6 w$ & 0.48 & 342 & 0.7 & 3 & $61 \%$ & $0 \%$ & $64 \%$ & 873 & +108 & -325 & 1.8 & 7 & 2741 \\
\hline Kap 8 Nat R & $7 w$ & 0.55 & 233 & 0.5 & 2 & $88 \%$ & $1 \%$ & $85 \%$ & 1944 & +362 & -825 & 3.7 & 13 & 4969 \\
\hline
\end{tabular}

${ }^{a}$ Samples indicated with an asterisk contain carbonates (see text, Table 2).

${ }^{b}$ Values have not been reconstructed to include $\mathrm{CO}_{2}$ lost to the bubble.

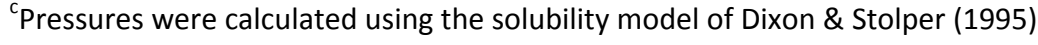

${ }^{\mathrm{d} D e p t h s}$ were calculated using a $3.5 \mathrm{~km} / \mathrm{kbar}$ gradient

e Percent of $\mathrm{CO}_{2}$ in the bubble is calculated using the mass balance approach described by Steele-Maclnnis et al. (2011) (see text and appendix).

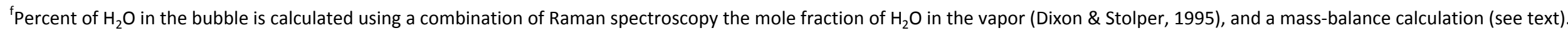

${ }^{g} \mathrm{CO}_{2}$ concentrations were reconstructed to include $\mathrm{CO}_{2}$ contained in the bubble measured in situ by Raman spectroscopy (see text)

${ }^{\mathrm{h}}$ Asymetrical error values are produced by propogating uncertainty through the mass balance calculations. See appendix for a discussion of error treatment.

${ }^{i} \mathrm{CO}_{2}$ concentrations reconstructed using the Ideal Gas Law (see text). 
Table 6: Major element and volatile chemistry of Fuego and Seguam melt inclusions (corrected for PEC)

\begin{tabular}{|c|c|c|c|c|c|c|c|c|c|c|c|}
\hline $\begin{array}{l}\text { Sample } \\
\text { Number }\end{array}$ & $\begin{array}{c}\text { Fuego } \\
5.3^{*}\end{array}$ & $\begin{array}{c}\text { Fuego } \\
9.2^{*}\end{array}$ & $\begin{array}{c}\text { Fuego } \\
11.1^{*}\end{array}$ & $\begin{array}{c}\text { Fuego } \\
12.3\end{array}$ & $\begin{array}{c}\text { Fuego } \\
15.1\end{array}$ & $\begin{array}{c}\text { Fuego } \\
19.1^{*}\end{array}$ & $\begin{array}{c}\text { Seguam } \\
2.1^{*}\end{array}$ & $\begin{array}{c}\text { Seguam } \\
5.2^{*}\end{array}$ & $\begin{array}{c}\text { Seguam } \\
6.1^{*}\end{array}$ & $\begin{array}{c}\text { Seguam } \\
7.5^{*}\end{array}$ & $\begin{array}{c}\text { Seguam } \\
8.3^{*}\end{array}$ \\
\hline Fo & 73 & 73 & 73 & 76 & 73 & 74 & 83 & 83 & 81 & 83 & 83 \\
\hline $\mathrm{SiO}_{2}$ & 51.806 & 50.064 & 49.944 & 48.768 & 52.827 & 50.160 & 50.580 & 50.845 & 49.649 & 50.811 & 49.193 \\
\hline $\mathrm{TiO}_{2}$ & 0.918 & 0.685 & 0.746 & 1.079 & 1.092 & 0.723 & 0.649 & 0.674 & 0.652 & 0.737 & 0.627 \\
\hline $\mathrm{Al}_{2} \mathrm{O}_{3}$ & 16.831 & 16.861 & 17.690 & 19.070 & 16.051 & 17.614 & 18.161 & 18.848 & 18.018 & 17.798 & 18.687 \\
\hline $\mathrm{Fe}_{2} \mathrm{O}_{3}$ & 1.599 & 1.683 & 1.412 & 1.192 & 1.491 & 1.431 & 0.872 & 0.787 & 0.998 & 0.944 & 0.893 \\
\hline $\mathrm{FeO}$ & 8.060 & 9.258 & 8.292 & 7.090 & 7.798 & 8.624 & 6.691 & 6.088 & 7.432 & 6.954 & 6.874 \\
\hline $\mathrm{MnO}$ & 0.209 & 0.161 & 0.221 & 0.137 & 0.202 & 0.190 & 0.082 & 0.067 & 0.200 & 0.121 & 0.107 \\
\hline MgO & 4.037 & 4.740 & 4.270 & 3.995 & 3.963 & 4.573 & 5.777 & 5.364 & 5.843 & 6.172 & 6.039 \\
\hline $\mathrm{CaO}$ & 7.337 & 8.062 & 9.040 & 9.557 & 7.912 & 8.655 & 10.249 & 10.134 & 10.533 & 9.613 & 10.587 \\
\hline $\mathrm{Na}_{2} \mathrm{O}$ & 3.830 & 3.107 & 2.982 & 3.232 & 3.396 & 2.783 & 2.492 & 2.827 & 2.303 & 2.436 & 2.450 \\
\hline $\mathrm{K}_{2} \mathrm{O}$ & 0.812 & 0.537 & 0.561 & 0.621 & 0.784 & 0.578 & 0.321 & 0.373 & 0.286 & 0.458 & 0.299 \\
\hline $\mathrm{Cr}_{2} \mathrm{O}_{3}$ & 0.000 & 0.000 & 0.000 & 0.000 & 0.000 & 0.000 & 0.045 & 0.012 & 0.024 & 0.049 & 0.036 \\
\hline $\mathrm{CO}_{2} \mathrm{ppm}$ & 188 & 495 & 512 & 691 & 269 & 490 & 99 & 191 & 113 & 179 & 182 \\
\hline $\mathrm{H}_{2} \mathrm{O}$ wt\% & 4.02 & 4.31 & 4.30 & 4.68 & 4.04 & 4.13 & 3.89 & 3.79 & 3.87 & 3.69 & 4.01 \\
\hline F ppm & 614 & 458 & 457 & 440 & 442 & 438 & 115 & 118 & 128 & 122 & 123 \\
\hline P ppm & 969 & 752 & 745 & 742 & 895 & 758 & 384 & 228 & 230 & 364 & 209 \\
\hline S ppm & 2092 & 2423 & 2490 & 2622 & 1627 & 2468 & 704 & 862 & 849 & 842 & 920 \\
\hline $\mathrm{Cl} \mathrm{ppm}$ & 1533 & 1192 & 1226 & 1296 & 1258 & 1262 & 547 & 566 & 576 & 622 & 567 \\
\hline$\%$ PEC & 1.73 & 1.65 & 1.73 & 0.85 & 0.42 & 1.89 & 3.19 & 2.91 & 1.03 & 2.87 & 2.72 \\
\hline
\end{tabular}


Table 6 (continued): Major element and volatile chemistry of Fuego and Seguam melt inclusions (corrected for PEC)

\begin{tabular}{|c|c|c|c|c|c|c|c|c|c|c|}
\hline $\begin{array}{l}\text { Sample } \\
\text { Number }\end{array}$ & $\begin{array}{c}\text { Seguam } \\
9.1 \\
\end{array}$ & $\begin{array}{c}\text { Seguam } \\
10.1^{*}\end{array}$ & $\begin{array}{c}\text { Seguam } \\
12.1 \\
\end{array}$ & $\begin{array}{c}\text { Seguam } \\
13.1^{*}\end{array}$ & $\begin{array}{c}\text { Seguam } \\
15.1^{*}\end{array}$ & $\begin{array}{c}\text { Seguam } \\
16.1^{*}\end{array}$ & $\begin{array}{c}\text { Seguam } \\
20\end{array}$ & $\begin{array}{c}\text { Seguam } \\
22.1^{*}\end{array}$ & $\begin{array}{c}\text { Seguam } \\
23.1^{*}\end{array}$ & $\begin{array}{c}\text { Seguam } \\
24.9^{*}\end{array}$ \\
\hline Fo & 83 & 82 & 83 & 83 & 82 & 82 & 75 & 83 & 83 & 83 \\
\hline $\mathrm{SiO}_{2}$ & 49.606 & 49.770 & 51.712 & 47.148 & 49.725 & 49.973 & 55.684 & 49.656 & 50.439 & 53.465 \\
\hline $\mathrm{TiO}_{2}$ & 0.680 & 0.852 & 0.551 & 0.609 & 0.640 & 0.629 & 1.041 & 0.626 & 0.613 & 0.701 \\
\hline $\mathrm{Al}_{2} \mathrm{O}_{3}$ & 18.123 & 17.573 & 17.688 & 18.749 & 17.778 & 18.525 & 14.975 & 18.341 & 17.373 & 14.861 \\
\hline $\mathrm{Fe}_{2} \mathrm{O}_{3}$ & 1.018 & 1.024 & 0.873 & 1.130 & 1.031 & 0.909 & 1.478 & 0.869 & 0.949 & 1.358 \\
\hline $\mathrm{FeO}$ & 7.526 & 7.399 & 6.683 & 7.813 & 7.710 & 6.881 & 8.199 & 7.178 & 7.265 & 8.309 \\
\hline $\mathrm{MnO}$ & 0.125 & 0.174 & 0.178 & 0.106 & 0.081 & 0.138 & 0.190 & 0.188 & 0.193 & 0.102 \\
\hline $\mathrm{MgO}$ & 6.518 & 6.306 & 5.835 & 6.539 & 6.458 & 5.697 & 4.684 & 6.321 & 6.409 & 7.457 \\
\hline $\mathrm{CaO}$ & 10.712 & 10.124 & 9.345 & 10.107 & 10.107 & 10.137 & 7.124 & 10.276 & 10.205 & 7.534 \\
\hline $\mathrm{Na}_{2} \mathrm{O}$ & 2.283 & 2.273 & 2.474 & 2.740 & 2.174 & 2.591 & 2.887 & 1.808 & 2.125 & 2.672 \\
\hline $\mathrm{K}_{2} \mathrm{O}$ & 0.318 & 0.357 & 0.416 & 0.359 & 0.286 & 0.310 & 0.921 & 0.333 & 0.270 & 0.473 \\
\hline $\mathrm{Cr}_{2} \mathrm{O}_{3}$ & 0.053 & 0.025 & 0.021 & 0.000 & 0.051 & 0.012 & 0.011 & 0.014 & 0.011 & 0.005 \\
\hline $\mathrm{CO}_{2} \mathrm{ppm}$ & 58 & 501 & 179 & 198 & 48 & 201 & 49 & 223 & 199 & 55 \\
\hline $\mathrm{H}_{2} \mathrm{O} w t \%$ & 2.87 & 3.86 & 4.09 & 4.46 & 3.78 & 3.99 & 2.57 & 4.16 & 3.93 & 2.92 \\
\hline F ppm & 114 & 109 & 119 & 150 & 124 & 127 & 268 & 128 & 122 & 110 \\
\hline P ppm & 251 & 316 & 277 & 249 & 218 & 223 & 642 & 262 & 302 & 473 \\
\hline S ppm & 706 & 1221 & 415 & 1125 & 785 & 891 & 621 & 974 & 883 & 372 \\
\hline $\mathrm{Cl} \mathrm{ppm}$ & 561 & 535 & 401 & 722 & 568 & 594 & 824 & 652 & 627 & 428 \\
\hline$\%$ PEC & 2.9 & 0.71 & 0 & 0 & 2.32 & 2.64 & 1.39 & 0.92 & 2.41 & 2.04 \\
\hline
\end{tabular}

Major element concentrations of the MI glass were measured by EPMA conducted at Virginia Tech. Volatile concentrations of the MI glass were measured by SIMS at CIW. Major element and volatile concentrations listed in this table have been corrected for PEC using Petrolog3 software (see methods). $\mathrm{CO}_{2}$ concentrations marked with an asterisk indicate a $\mathrm{MI}$ where $\mathrm{CO}_{2}$ was detected in the vapor bubble. The $\mathrm{CO}_{2}$ concentrations in this table have not been reconstructed to include $\mathrm{CO}_{2}$ in the bubble. 